\title{
Theoretical investigation of the eight low-lying electronic states of the cis- and trans-nitric oxide dimers and its isomerization using multiconfigurational second-order perturbation theory (CASPT2)
}

\author{
R. Sayós ${ }^{\text {a) }}$ and R. Valero \\ Departament de Química Física i Centre de Recerca de Química Teòrica, Universitat de Barcelona, \\ C/Martí i Franquès 1, 08028 Barcelona, Spain \\ J. M. Anglada \\ Institut d'Investigacions Químiques i Ambientals de Barcelona, CID-CSIC C/Jordi Girona 18-26, \\ 08034 Barcelona, Spain \\ Miguel González ${ }^{\mathrm{a})}$ \\ Departament de Química Física i Centre de Recerca de Química Teòrica, Universitat de Barcelona, \\ C/Martí i Franquès 1, 08028 Barcelona, Spain
}

(Received 12 October 1999; accepted 27 January 2000)

\begin{abstract}
In this work we have carried out $a b$ initio electronic structure calculations, CASSCF/CASPT2 and CASSCF/MRCI-SD+Q with several Pople's and correlation-consistent Dunning's basis sets, of the planar cis- and trans-NO dimers for the lowest eight electronic (singlet and triplet) states. The geometry, frequencies, dipole moment, binding energy, and vertical excitation energies are predicted with an accuracy close to or even better than the best reported ab initio previous results for some of these properties, and in very good agreement with the available experimental data. CASPT2 optimized geometries show the existence of at least four shallow NO-dimers (i.e., two cis-(NO) $)_{2}\left({ }^{1} A_{1}\right.$ and $\left.{ }^{3} B_{2}\right)$ and two trans-(NO) $2\left({ }^{1} A_{g}\right.$ and $\left.\left.{ }^{3} A_{u}\right)\right)$, although CASSCF optimization with CASPT2 pointwise calculations indicate the existence of other less stable dimers, on the excited states. Vertical excitation energies were calculated for these four dimers. For the cis-NO dimer, the ordering and the energy spacings between the excited states (i.e., ${ }^{1} A_{1},{ }^{3} B_{2},{ }^{1} B_{2}, 2$ nd ${ }^{1} A_{1},{ }^{1} A_{2}$, ${ }^{3} A_{2},{ }^{3} B_{1}, 2$ nd ${ }^{3} B_{1}$ ) are very similar to those found in a recent MRCI-SD study. The singlet cis-NO dimer $\left({ }^{1} A_{1}\right)$ is the most stable one in almost quantitative accord with the experimental data, and in disagreement with previous density functional theory studies. A nonplanar transition state for the singlet trans $\leftrightarrow$ cis isomerization has also been fully characterized. This leads to an almost negligible energy barrier which would originate a rapid isomerization to the most stable cis-NO dimer at low temperatures, in accord with the experimental difficulties to measure the properties of the trans-NO dimer. Not only are basis set superposition error corrections necessary to evaluate accurately the binding energies, but also to determine the $\mathrm{NN}$ distance of these symmetrical dimers. Some problems regarding the symmetry of the wave function were found for the symmetrical NO dimers and for the $\mathrm{NO}+\mathrm{NO}$ asymptote, and several approximate solutions were proposed. (c) 2000 American Institute of Physics. [S0021-9606(00)31115-1]
\end{abstract}

\section{INTRODUCTION}

The $\mathrm{NO}\left({ }^{2} \Pi\right)$ molecule is a small and stable free radical which shows a great tendency to form relatively stable neutral dimers with a binding energy larger than those of the typical van der Waals dimers. ${ }^{1,2}$ These dimers are involved in many different chemical processes as will be summarized below.

There have been many experimental studies mainly aimed at determining the structure of the planar symmetrical cis- $(\mathrm{NO})_{2}$ structure $\left(C_{2 v}\right.$ symmetry $)$ and its spectroscopic constants in gas, liquid, solid-phase, and in matrix-isolated environments $\left(\mathrm{Ar}, \mathrm{N}_{2}, \mathrm{CCl}_{4}, \ldots\right)$. Thus, infrared (IR) and Raman spectroscopy in gas-phase, ${ }^{3-6}$ solid-phase, ${ }^{7}$ and in iso-

\footnotetext{
a) Authors to whom correspondence should be addressed. Electronic mail: r.sayos@qf.ub.es, miguel@qf.ub.es
}

lated argon matrices ${ }^{8}$ of ${ }^{14} \mathrm{NO}-{ }^{14} \mathrm{NO}$ and its isotopomers (with ${ }^{15} \mathrm{~N}$ or ${ }^{18} \mathrm{O}$ ) have yielded abundant data about the vibrational frequencies, force fields, geometry $\left(R_{\mathrm{NN}}\right.$ $\left.=2.2630(12) \AA, R_{\mathrm{NO}}=1.1515(3) \AA, \angle \mathrm{ONN}=97.17(5)^{\circ}\right)^{4}$ and binding energies $\left(D_{0}=1.8-2.3 \mathrm{kcal} / \mathrm{mol}\right)$. Pulsed molecular beam and Doppler profile analysis techniques ${ }^{9,10}$ have been used to measure the IR photodissociation spectra, the product state distributions, and the predissociation lifetimes of vibrationally excited cis-nitric oxide dimer. The LIF/subDoppler study of the vector correlations in the UV (193 nm) photodissociation of the gas-phase NO dimer has shown that the planar cis- $(\mathrm{NO})_{2}$ dissociates producing electronically excited NO fragments, keeping its planarity. ${ }^{11,12}$

Microwave and radiofrequency spectroscopies ${ }^{13-16}$ have confirmed the IR structural parameters for the planar cis-NO dimer and have assumed that the ground electronic state is a singlet state. A single determination of its electric dipole 
moment $(0.17120(2) D)$ has been also done. ${ }^{13}$ of

The IR spectroscopic study of the dissociation constant

$$
\mathrm{NO}\left({ }^{2} \Pi\right)+\mathrm{NO}\left({ }^{2} \Pi\right) \Leftrightarrow(\mathrm{NO})_{2},
$$

in a nitrogen matrix ${ }^{17}$ gives a value of $K_{c}=2.2$ $\times 10^{19}$ molecule $\cdot \mathrm{cm}^{3}$ which does not change between 24 and $32 \mathrm{~K}$. This value is smaller than the value measured by absorption spectroscopy in the gas-phase $\left(K_{c}=(3 \pm 2)\right.$ $\times 10^{21}$ molecule $\cdot \mathrm{cm}^{3}$ at $\left.100 \mathrm{~K}\right){ }^{18}$ Therefore, it was concluded that the effect of the solvation in the matrix on the binding energy of the dimer should be lower than $10 \%$.

Experimental information about the trans-NO dimer is very scarce, possibly due to its much lower stability. Thus, some weak IR active bands have been found in nitrogen ${ }^{8,17}$ and $\operatorname{argon}^{8}$ matrix experiments, which could be assigned to the trans-NO dimer. A value of the ratio $\mathrm{N}_{\text {cis }} / \mathrm{N}_{\text {trans }} \approx 4.85$ (almost constant within the 24-32 K range) has been derived from IR spectroscopy in $\mathrm{N}_{2}$ matrix. ${ }^{17}$

Experimental studies have been carried out about the photodissociation dynamics of adsorbed NO dimers on several surfaces, such as $\mathrm{Ag}(111),{ }^{19} \mathrm{Pd}(111),{ }^{20} \mathrm{MgF}_{2}$ (Ref. 21), or $\mathrm{LiF}(001),{ }^{22,23}$ at different wavelengths $(193-270 \mathrm{~nm})$ :

$$
(\mathrm{NO})_{2(\mathrm{ad})} \rightarrow \mathrm{NO}\left(X^{2} \Pi\right)+\mathrm{NO}\left(A^{2} \Sigma^{+} \text {or } B^{2} \Pi\right) .
$$

They have shown energy distributions that can be rationalized by assuming different equilibrium geometries between the ground and excited states of the adsorbed NO dimer. Moreover, the NO dimer adsorbed on the $\mathrm{Ag}(111)$ presents a surprising low-temperature reactivity producing directly $\mathrm{N}_{2} \mathrm{O}$ adsorbed molecules, ${ }^{24,25}$

$\mathrm{NO}\left({ }^{2} \Pi\right)+\mathrm{NO}\left({ }^{2} \Pi\right) \rightarrow(\mathrm{NO})_{2(\mathrm{ad})} \rightarrow \mathrm{N}_{2} \mathrm{O}\left(X^{1} \Sigma^{+}\right)_{(\mathrm{ad})}+\mathrm{O}\left({ }^{3} P\right)$,

with an apparent activation energy of $1.7 \mathrm{kcal} / \mathrm{mol}$ and a low preexponential factor of $3500 \mathrm{~s}^{-1}$ in the $70-90 \mathrm{~K}$ interval. This fast surface reaction via the NO dimer contrasts with the corresponding endothermic gas-phase reaction, which has a very high activation energy and possibly takes place with a little influence of the NO dimer. In fact, the reverse and most favorable exothermic reaction

$$
\begin{aligned}
\mathrm{O}\left({ }^{3} P\right)+\mathrm{N}_{2} \mathrm{O}\left(X^{1} \Sigma^{+}\right) \rightarrow & \mathrm{NO}\left({ }^{2} \Pi\right)+\mathrm{NO}\left({ }^{2} \Pi\right) \\
& \Delta \mathrm{H}^{\circ}{ }_{298 \mathrm{~K}}=-36.0 \mathrm{kcal} \cdot \mathrm{mol}^{-1},
\end{aligned}
$$

is only accessible at very high temperatures $\left(E_{a}\right.$ $=26.6 \mathrm{kcal} \cdot \mathrm{mol}^{-1}$ in the $\left.1200-4100 \mathrm{~K} \mathrm{range}\right){ }^{26,27}$

The transient formation of $(\mathrm{NO})_{2}$ collision complexes derived from cis- or trans-dimers can facilitate the $V-T$ energy transfer in the vibrational self-relaxation of $\mathrm{NO}\left(X^{2} \Pi ; v\right)$ molecules at low temperatures $(7-85 \mathrm{~K})$ :

$\mathrm{NO}(v=3)+\mathrm{NO}(v=0) \rightarrow \mathrm{NO}\left(v^{\prime}<3\right)+\mathrm{NO}\left(v^{\prime}=0\right)$.

In these conditions it is proposed that only the lowest singlet and triplet surfaces can be accessed adiabatically and therefore can give place to the transient collision complexes. ${ }^{28}$ The same surfaces (four singlet states and four triplet states) involved in the dimer dissociation are probed by $\mathrm{NO}+\mathrm{NO}$ collisions, although with a different distribution of initial states. Thus, an influence in the rotationally inelastic collisions of $\mathrm{NO}\left(X^{2} \Pi_{1 / 2}\right)$ is also expected: ${ }^{29}$

$$
\begin{aligned}
\mathrm{NO}(v=0, j \leqslant 2.5)+\mathrm{NO}(v=0, j \leqslant 2.5) \\
\rightarrow \mathrm{NO}\left(v^{\prime}=0, j^{\prime}\right)+\mathrm{NO}\left(v^{\prime \prime}=0, j^{\prime \prime}\right) .
\end{aligned}
$$

At very highly vibrationally excited $\mathrm{NO}(v \gg 1)$ the selfrelaxation rate constants increase 200 times with respect to $\mathrm{NO}(v=1)$ and a large isotope effect is observed. ${ }^{30}$ This unusual fast increase may be due to the predicted high energy $(\mathrm{NO})_{2}$ isomer complexes ${ }^{31,32}$ which become accessible in this energy regime.

It has also been proposed that cis- and trans-NO dimers can form metastable open-chain oligomers at extreme pressures. $^{33}$

From a theoretical point of view, the NO dimers have been widely studied by different density functional theory (DFT) and $a b$ initio quantum chemistry methods. Nevertheless, these studies have usually supplied only partial data about the properties of some isomers of the NO dimer. Thus, the first studies at an $a b$ initio SCF level gave too short NN distances and ascribed less stability to cis- than trans-NO dimer. $^{34-36}$ Semiempirical calculations (MNDO or AM1) ${ }^{33}$ gave also rather poor results, although AM1 indicated that cis- was more stable than trans-dimer. Correlation treatments [e.g., MP2, CPF, or $\mathrm{CCSD}^{37}$ and $\mathrm{QCISD}(\mathrm{T})$ or $\left.\operatorname{CCSD}(\mathrm{T})\right]^{38}$ were necessary to produce longer NN distances in better agreement with the experimental values. Accurate multireference CI (MRCI) calculations based in CASSCF molecular orbitals (MO) have been recently performed in order to obtain reliable geometries and binding energies of the cis-NO dimer. Thus, Roos et al. ${ }^{39}$ have carried out MRCI and ACPF calculations with extended atomic natural orbital (ANO) basis sets, including also the effect of the basis set superposition error (BSSE) and additional effects, such as the correlation of core electrons and relativistic corrections. Their best calculation gives an optimal geometry of $R_{\mathrm{NN}}=2.284 \AA$, $R_{\mathrm{NO}}=1.149 \AA$, and $\angle \mathrm{NNO}=96.1^{\circ}$ and a binding energy (i.e., $D_{e}$ ) equal to $3.3 \mathrm{kcal} / \mathrm{mol}$, values close to the experimental ones. East ${ }^{40}$ has investigated the 16 electronic states arising from $\mathrm{NO}\left(X^{2} \Pi\right)+\mathrm{NO}\left(X^{2} \Pi\right)$ and $\mathrm{NO}^{+}\left(X^{1} \Sigma^{+}\right)$ $+\mathrm{NO}^{-}\left(X^{3} \Sigma^{-}\right)$asymptotes of the trans- and cis-NO dimers using various $a b$ initio levels of theory $[\mathrm{MRCI}, \operatorname{CCSD}(\mathrm{T}), \ldots]$. The results suggest that only the ground singlet state should have a minimum $\left[\right.$ cis- $\left.(\mathrm{NO})_{2}\right]$ below the $\mathrm{NO}+\mathrm{NO}$ asymptote. However, only vertical energies without geometrical optimization were calculated.

Numerous recent DFT studies ${ }^{41-46}$ have tried to derive the geometry of the cis- and trans-NO dimers, but they have been unable to predict properly and simultaneously, the geometry and the binding energy of the cis-NO dimer, and its relative stability in comparison with the trans-NO dimer. Thus, Canty et al. ${ }^{45}$ found a stability of the cis-NO dimer with respect to the trans-NO dimer within the range 3.2-5.4 $\mathrm{kcal} / \mathrm{mol}$ depending on the DFT method, and an estimate of the energy barrier trans $\rightarrow$ cis of about $1.9 \mathrm{kcal} / \mathrm{mol}$ at the local spin density approximation (LSDA) level. All functional combinations predicted that the cis-NO dimer had 
longer $\mathrm{NN}$ distances and smaller $\angle \mathrm{ONN}$ bond angles than the trans-NO dimer, although in all cases the $\mathrm{NN}$ distances were smaller than the experimental ones. Binding energies were not reported. Salahub et al. ${ }^{46}$ have performed a DFT study including BSSE corrections and they concluded an unexpected greater stability for the triplet state in both $c i s$ - and trans-NO dimers at their fully optimized geometries, in clear disagreement with the assumption made in most of the preceding ab initio and DFT studies. They suggest that a mixture of singlet and triplet NO dimers could be found in the experimental environment.

Low-energy cis- and trans-ONON planar isomers have also been studied by $a b$ initio $^{40}$ and DFT methods ${ }^{41}$ in their lowest singlet and triplet states, showing less stability than the corresponding ONNO dimers. However, major attention has been paid to the study of high-energy $\mathrm{N}_{2} \mathrm{O}_{2}$ isomers (approximately $40-80 \mathrm{kcal} / \mathrm{mol}$ above $\left.\mathrm{NO}\left(X^{2} \Pi\right)+\mathrm{NO}\left(X^{2} \Pi\right)\right)$ that could have potential application in developing new energetic materials for use in high specific impulse fuels. Several experiments (e.g., molecular beam stimulated emission pumping, ${ }^{30,47}$ or photoelectron spectroscopy of the $\mathrm{N}_{2} \mathrm{O}_{2}^{-}$ anion $)^{48}$ provide indirect evidence for the possible existence of this kind of isomers. Much more effort has been dedicated to their theoretical study. Ab initio ${ }^{31-32,49-53}$ studies have allowed the characterization of several cyclic $\left(C_{2 v}, D_{2 h}\right.$, and $C_{s}$ ), and other planar (e.g., asymmetric OONN) or nonplanar (e.g., $C_{2 v}$ butterfly-like) isomers that could be involved in reactions such as $\mathrm{O}\left({ }^{3} P,{ }^{1} D\right)$ with $\mathrm{N}_{2} \mathrm{O}$ or $\mathrm{N}\left({ }^{2} D,{ }^{2} P\right)+\mathrm{NO}_{2}$.

The aim of this work is to present an ab initio study that can furnish the main properties of the cis- and trans-NO dimers (i.e., geometry, vibrational frequencies, electric dipole moment, binding energy, vertical energies,..) and also information about the trans $\leftrightarrow$ cis isomerization, all at the same level of theory and with a general good agreement with the available experimental data. Moreover, the calculation of the first excited states (singlets and triplets) can allow a clarification whether the singlet or the triplet state is the ground state of these dimers at the optimized geometries of the lowest singlet and triplet states.

\section{METHODOLOGY}

The NO dimers have been studied using $a b$ initio electronic structure methods employing complete active space self-consistent field (CASSCF) wave functions. Two kinds of wave functions were used. The description of the active spaces in the $(\mathrm{NO})_{2}$ species can be done in terms of the orbital structure of the NO monomers. The electronic configuration of an NO molecule in the $X^{2} \Pi$ state is: $\quad\left(\sigma_{1 s}\right)^{2}\left(\sigma_{1 s}^{*}\right)^{2}\left(\sigma_{2 s}\right)^{2}\left(\sigma_{2 s}^{*}\right)^{2}\left(\sigma_{2 p z}\right)^{2}\left(\pi_{2 p}\right)^{2}\left(\pi_{2 p}^{\prime}\right)^{2}\left(\pi_{2 p}^{*}\right)^{1}$ $\times\left(\pi_{2 p}^{\prime *}\right)^{0}\left(\sigma_{2 p z}^{*}\right)^{0}$, where the character of each of the molecular orbitals is indicated. Some unoccupied orbitals are also indicated because they facilitate the following explanation on the active spaces chosen for the CASSCF wave functions. The first one, denoted as $(14,12)$ (i.e., 14 active electrons distributed in 12 active orbitals with the appropriate symmetry and spin), arises from the seven NO electrons in the $\sigma_{2 p z}, \pi_{2 p}, \pi_{2 p}^{\prime}$ and $\pi_{2 p}^{*}$ plus the unoccupied $\pi_{2 p}^{\prime *}$ and $\sigma_{2 p z}^{*}$ orbitals; each orbital in a $(\mathrm{NO})_{2}$ species is the + or - combination of two of these orbitals, one taken from each NO monomer. The $(18,14)$ active space is constructed from this smaller active space by simply adding the four electrons and two orbitals deriving from the two electrons in the $\sigma_{2 s}^{*}$ orbital of each one of the monomers, which is mainly of $\mathrm{N}$ atomic type.

Second-order multiconfigurational perturbation theory (CASPT2) has been used to compute the dynamic correlation energy. ${ }^{54,55}$ The zeroth-order wave function was the CASSCF one in all the calculations. All the elements of the Fock matrix were included in the calculations (PT2F) instead of the less accurate although cheaper choice of considering only the diagonal terms (PT2D). The G2 correction $^{56}$ to the Fock matrix, which produces a balanced treatment of both open-shell and closed-shell configurations, was included in all the calculations. Several tests of our own on elementary reactions involving $\mathrm{N}$ and $\mathrm{O}$ (e.g., $\mathrm{O}\left({ }^{1} D\right)+\mathrm{N}_{2} \mathrm{O}, \mathrm{N}\left({ }^{4} S,{ }^{2} D\right)$ $\left.+\mathrm{O}_{2}, \ldots\right)$ showed that this correction gave good results when compared with the experimental data. In fact, the validity of the CASPT2 method, which is essentially size consistent, has been widely illustrated in several reviews. ${ }^{56-60}$ Thus, equilibrium geometries are predicted with an accuracy better than $0.01 \AA$ for bond distances and $0^{\circ}-2^{\circ}$ for bond angles. The excitation and dissociation energies compare very well (i.e., in most cases below $1 \mathrm{kcal} / \mathrm{mol}$ ) with the corresponding FCI and MRCI values, and also with the experimental values, ${ }^{56}$ once the $\mathrm{G}$ correction $(\mathrm{G} 1, \mathrm{G} 2$ or G3) along with saturated basis sets and all active valence electrons are considered.

Three kinds of cartesian Gaussian basis sets were employed in this study for oxygen and nitrogen: the standard 6-31G $(d), 6-311 \mathrm{G}(2 d)$, and $6-311 \mathrm{G}+(2 d)$ basis sets of Pople and co-workers. ${ }^{61-63}$ The standard correlationconsistent (cc-pVnZ, $n=\mathrm{D}, \mathrm{T}, \mathrm{Q}$ ) basis sets of Dunning and co-workers ${ }^{64}$ were also used. The first basis sets have been used in $\mathrm{DFT}^{42-44}$ and $a b$ initio $^{31,32,49}$ studies of several NO dimers with good results. The Dunning's correlationconsistent basis sets have produced excellent results in different benchmark calculations (e.g., for the binding energy and the structure of the HF dimer) ${ }^{65}$ and also in the study of excited states of various NO dimers. ${ }^{40}$ The basis sets were obtained from the extensible computational chemistry environment basis set database, version 1.0, as developed and distributed by the Molecular Science Computing Facility. ${ }^{66}$ All our calculations were carried out using the MOLCAS 4.1 quantum chemistry program package. ${ }^{67}$

All the stationary points have been characterized at the CASSCF level of calculation using analytic gradients and numerical Hessian matrix. Harmonic frequencies were calculated for the most abundant isotopes $\left({ }^{14} \mathrm{~N}\right.$ and $\left.{ }^{16} \mathrm{O}\right)$. Nevertheless, at the CASPT2 level, the geometrical optimization and the calculation of the harmonic frequencies were performed fitting different sets of pointwise calculations by means of the SURVIBTM code. ${ }^{68}$ Around 60 CASPT2 points were calculated in different geometries $\left(C_{2 v}, C_{s}\right.$, or $\left.C_{2}\right)$ in the vicinity of the chosen stationary point (i.e., small increments $\leqslant 0.01 \AA$ or $1^{\circ}$ ). Additional points were added until convergence was achieved in the geometry, energy, and harmonic frequencies derived by means of the least-squares fitting procedure. A symmetry adapted internal coordinates ex- 
TABLE I. Properties of the optimized $\mathrm{NO}\left({ }^{2} \Pi\right)$ molecule at various levels of theory.

\begin{tabular}{|c|c|c|c|c|c|c|c|c|}
\hline Method & $\begin{array}{l}\text { Energy } \\
(\mathrm{H})\end{array}$ & $\begin{array}{c}R \\
(\AA)\end{array}$ & $\begin{array}{c}D_{e}{ }^{\mathrm{a}} \\
(\mathrm{kcal} / \mathrm{mol})\end{array}$ & $\begin{array}{c}\mathrm{ZVE}^{\mathrm{b}} \\
(\mathrm{kcal} / \mathrm{mol})\end{array}$ & $\begin{array}{c}\nu_{e} \\
\left(\mathrm{~cm}^{-1}\right)\end{array}$ & $\begin{array}{l}\mu_{e} \\
\text { (D) }\end{array}$ & $\begin{array}{c}\bar{\alpha} \\
\left(\AA^{3}\right)\end{array}$ & $\begin{array}{c}\gamma \\
\left(\AA^{3}\right)\end{array}$ \\
\hline $\begin{array}{l}\operatorname{CASSCF}(7,6): \\
/ 6-31 \mathrm{G}(d)\end{array}$ & -129.352450 & 1.1678 & $119.96(135.98)$ & 2.74 & 1915.1 & 0.1728 & 1.089 & 1.004 \\
\hline$/ 6-311 \mathrm{G}(2 d)$ & -129.391802 & 1.1586 & $122.63(140.20)$ & 2.70 & 1887.1 & 0.2299 & 1.258 & 0.829 \\
\hline /cc-pVTZ & -129.401372 & 1.1563 & $123.61(148.77)$ & 2.73 & 1908.3 & 0.2267 & 1.229 & 0.996 \\
\hline $\begin{array}{l}\operatorname{CASSCF}(9,7) \\
/ 6-311 \mathrm{G}(2 d)\end{array}$ & -129.397689 & 1.1606 & $126.32(141.29)$ & 2.68 & 1877.6 & 0.1865 & 1.258 & 0.847 \\
\hline /cc-pVTZ & -129.407198 & 1.1583 & $128.04(149.83)$ & 2.71 & 1895.7 & 0.1836 & 1.302 & 0.900 \\
\hline $\begin{array}{l}\text { CASPT2 }(9,7) \\
/ 6-311 \mathrm{G}(2 d)\end{array}$ & -129.695025 & 1.1598 & 141.27 & 2.65 & $1856.7^{\mathrm{c}}$ & 0.1538 & 1.283 & 0.881 \\
\hline Experimental $^{\mathrm{d}}$ & $\cdots$ & 1.1508 & $152.53^{\mathrm{e}}$ & 2.72 & $1904.204^{\mathrm{f}}$ & $0.1574^{\mathrm{g}}$ & 1.73 & 0.85 \\
\hline
\end{tabular}

${ }^{a}$ Dissociation energy with respect to $\mathrm{N}\left({ }^{4} S\right)+\mathrm{O}\left({ }^{3} P\right)$ at $20 \AA$. The CASPT2 energies at the CASSCF geometries are given in parentheses.

${ }^{\mathrm{b}}$ Harmonic zero-point vibrational energy.

${ }^{\mathrm{c} S}$ Spectroscopic constants obtained by an analytical fit of 63 ab initio points by means of Eq. (12): $\nu_{e} x_{e}$ $=13.324, \alpha_{e}=0.01713, \bar{D}_{e}=5.487 \times 10^{-6}, B_{e}=1.6785\left(\right.$ in cm$\left.^{-1}\right)$.

${ }^{\mathrm{d}}$ References $74-76$.

${ }^{\mathrm{e}}$ The experimental $D_{e}$ value modified to eliminate the spin-orbit coupling (not included in the theoretical calculations) is almost coincident $(152.58 \mathrm{kcal} / \mathrm{mol})$.

${ }^{\mathrm{f}}$ Experimental spectroscopic constants for $\mathrm{NO}\left(X^{2} \Pi_{1 / 2}\right): \nu_{e} x_{e}=14.075, \alpha_{e}=0.0171, \bar{D}_{e}=5.466 \times 10^{-6}$, and $B_{e}=1.6720$ (in $\mathrm{cm}^{-1}$ ) (Ref. 74).

${ }^{\mathrm{g}}$ Electric dipole moment for $\mathrm{NO}\left(X^{2} \Pi_{1 / 2}\right)$ at $v=0$.

pansion in the distances [Simons-Parr-Finlan (SPF) expansions $]^{69,70}$ and in the bond angles and the dihedral angle (Taylor expansions) were used with several degrees of the polynomial:

$$
R_{\mathrm{SPF}}=\frac{R-R_{e}}{R} .
$$

Once the stationary point was located, the potential energy was reexpanded in a Taylor series polynomial of the normal mode vectors, and finally, perturbation theory was used to determine the spectroscopic constants.

Some single point uncontracted multireference SD-CI (MRCI) calculations with the inclusion of the Davidson correction $(Q)$ based on the same CASSCF MOs were also performed to compare with the CASPT2 results (see details in the next section). Moreover, some DFT optimizations were also carried out to compare with other results from the literature (see last section).

The permanent dipole moment $\left(\mu_{e}\right)$ and the parallel $\left(\alpha_{\|}\right)$and perpendicular $\left(\alpha_{\perp}\right)$ components of the dipole polarizability were calculated for the NO monomer. Dipole moments were also determined for the NO dimers. These electric properties can be determined numerically by calculating the total energy $(E)$ at different values of an uniform external electric field $(F){ }^{65,71}$ The dipole moment and the polarizability components were evaluated using first- and second-order numerical derivatives of the energy (two- and three-point formulas, respectively) with respect to $F$ from the fielddependent energy equation ${ }^{72}$

$$
E \approx E_{0}-\vec{\mu}_{0} \vec{F}-\frac{1}{2} \vec{F} \alpha \vec{F},
$$

where the subscript refers to the property at $F=0$. It was checked that a parabolic fit of several energies calculated at different values of $F$, where it was chosen with steps $\leqslant \pm 0.002$ a.u. gave the same results as the direct numerical differentiation at a single value of $F$.

For the accurate calculation of intermolecular interactions using ab initio methods it is necessary to include the basis set superposition error (BSSE) because the different number of basis functions in each unit originates an unbalanced treatment of the monomer and the dimer. The standard counterpoise (CP) correction proposed by Boys and Bernardi ${ }^{73}$ has been used,

$$
\mathrm{BSSE}=2 \times\left(E_{\mathrm{NO}}^{f}-E_{\mathrm{NO}}^{f *}\right),
$$

and the binding energy (BE) was calculated as

$$
\mathrm{BE}=D_{e}=2 \times E_{\mathrm{NO}}^{\mathrm{opt}}-E_{\mathrm{ONNO}},
$$

where the superscripts "opt" and " $f$ " denote the individually optimized and the monomer frozen in its supermolecular (dimer) geometry, respectively, and the asterisk denotes the monomer calculated with ghost orbitals. Thus, the CPcorrected binding energy will be equal to

$$
\mathrm{BE}_{\mathrm{CP}}=\mathrm{BE}-\mathrm{BSSE} \text {. }
$$

\section{RESULTS AND DISCUSSION}

\section{A. Calculated properties of the NO monomer}

Calculated spectroscopic constants and electric properties of the NO molecule are shown in Table I. The calculated equilibrium bond lengths at the CASSCF or CASPT2 level are quite close to each other and to the corresponding experimental value. The dissociation energies differ more from the experimental value. The best value [CASSCF $(9,7) / \mathrm{cc}-\mathrm{pVTZ}]$ shows a relative error of about $1.8 \%$. However, a clear increase in the accuracy is observed when the quality of the basis set is increased as it has also been shown in benchmark 
TABLE II. Properties of the optimized cis-NO dimer $\left({ }^{1} A_{1}\right)$ at various levels of theory.

\begin{tabular}{|c|c|c|c|c|c|c|c|c|c|c|c|c|c|}
\hline \multirow[b]{2}{*}{ Method } & \multirow{2}{*}{$\begin{array}{l}\text { Energy } \\
(\mathrm{H})\end{array}$} & \multirow{2}{*}{$\begin{array}{c}R_{\mathrm{NN}} \\
(\AA)\end{array}$} & \multirow{2}{*}{$\begin{array}{l}R_{\mathrm{NO}} \\
(\AA)\end{array}$} & \multirow{2}{*}{$\begin{array}{l}\mathrm{N}_{\mathrm{N}} \mathrm{O} \\
(o)\end{array}$} & \multirow{2}{*}{$\begin{array}{l}\mu_{e} \\
\text { (D) }\end{array}$} & \multirow{2}{*}{$\begin{array}{c}\mathrm{BE}^{\mathrm{a}} \\
(\mathrm{kcal} / \mathrm{mol})\end{array}$} & \multirow{2}{*}{$\begin{array}{c}\Delta \mathrm{ZPE}^{\mathrm{b}} \\
(\mathrm{kcal} / \mathrm{mol})\end{array}$} & \multicolumn{6}{|c|}{$\nu_{i}\left(\mathrm{~cm}^{-1}\right)^{\mathrm{c}}$} \\
\hline & & & & & & & & $a_{1}$ & $a_{1}$ & $a_{1}$ & $b_{1}$ & $b_{1}$ & $a_{2}$ \\
\hline $\begin{array}{l}\text { CASSCF }(14,12) ; \\
/ 6-31 \mathrm{G}(d)\end{array}$ & -258.705373 & 3.0945 & 1.1675 & 88.8 & 0.3314 & $0.30(1.66)$ & 0.48 & 102.3 & 39.6 & 1917.6 & 150.2 & 1911.2 & 47.5 \\
\hline$/ 6-31 \mathrm{G}(2 d)$ & -258.784026 & 3.3082 & 1.1585 & 86.8 & 0.4433 & $0.26(1.39)$ & 0.39 & 85.0 & 31.2 & 1890.5 & 113.2 & 1886.2 & 41.0 \\
\hline $\begin{array}{l}\text { CASSCF }(18,14) \\
/ 6-311 \mathrm{G}(2 d)\end{array}$ & -258.795864 & 3.0623 & 1.1603 & 90.8 & 0.3483 & $0.30(1.81)$ & 0.50 & 97.9 & 38.0 & 1876.3 & 156.6 & 1868.9 & 58.1 \\
\hline $\begin{array}{l}\text { CASPT2 }(18,14) \\
/ 6-311 \mathrm{G}(2 d)^{\mathrm{d}}\end{array}$ & -259.396920 & 2.3271 & 1.1594 & 94.5 & 0.2239 & 4.31 & 1.43 & 275.5 & 177.9 & 1849.5 & 418.0 & 1788.8 & 190.2 \\
\hline $\begin{array}{l}\operatorname{CCSD}(T)^{\mathrm{e}} \\
\text { /aug-cc-pVDZ }\end{array}$ & $\cdots$ & 2.227 & 1.169 & 96.2 & $\cdots$ & $\cdots$ & $\cdots$ & 279 & 201 & $\cdots$ & 536 & $\cdots$ & 191 \\
\hline $\begin{array}{l}\mathrm{ACPF}(2)+\mathrm{BSSE} \\
/ \mathrm{ANO}[6 s 5 p 3 d 2 f]^{\mathrm{f}}\end{array}$ & $\cdots$ & 2.284 & 1.149 & 96.1 & $\cdots$ & 3.3 & $\cdots$ & $\cdots$ & $\cdots$ & $\cdots$ & $\cdots$ & $\cdots$ & $\cdots$ \\
\hline $\begin{array}{l}\text { CASPT2D }(14,12) \\
/ A N O[5 \mathrm{~s} 4 \mathrm{p} 3 \mathrm{~d} 2 \mathrm{f}]^{\mathrm{g}}\end{array}$ & -259.49529 & 2.30 & 1.152 & 101.4 & $\cdots$ & 4.61 & $\ldots$ & $\cdots$ & $\cdots$ & $\cdots$ & $\cdots$ & $\cdots$ & $\cdots$ \\
\hline $\begin{array}{l}\text { DFT-B3LYP } \\
/ 6-311 \mathrm{G}+(d)^{\mathrm{h}}\end{array}$ & -259.85843 & 1.991 & 1.149 & 101.4 & $\cdots$ & -3.00 & $\cdots$ & 316 & 408 & 1960 & 721 & 1797 & 241 \\
\hline $\begin{array}{l}\text { DFT-PLAP1 XC } \\
/ 6-311 \mathrm{G}+(d)^{\mathrm{i}}\end{array}$ & $\cdots$ & 2.121 & 1.161 & 99.76 & 0.100 & $8.18(7.78)$ & $\cdots$ & 256.4 & 369.4 & 1848.0 & 631.7 & 1677.8 & 224.4 \\
\hline
\end{tabular}

${ }^{a}$ Binding energy with respect to $\mathrm{NO}+\mathrm{NO}$ at $20 \AA$. The CASPT2 energies are given in parentheses.

${ }^{\mathrm{b}}$ Difference of calculated zero-point vibrational energy between the cis-(NO) $)_{2}$ dimer and the $\mathrm{NO}+\mathrm{NO}$ asymptotic energy (including $\nu_{e} x_{e}$ when available). $\mathrm{BE}-\Delta \mathrm{ZPE}=D_{o}$ is the binding energy of the van der Waals dimer with zero-point vibrational energy corrections.

${ }^{c}$ Harmonic vibrational frequencies which correspond to: sym. NNO bend, NN str., sym. NO str., asym. NNO bend, asym. NO str. and torsion modes, respectively. The molecule is lying in the $X Z$ plane, with the $z$ axis as the $C_{2}$ axis for the $\left({ }^{14} \mathrm{~N}^{16} \mathrm{O}\right)_{2}$ dimer.

${ }^{\mathrm{d}}$ Harmonic frequencies and geometry derived by means of an analytical fit of $59 a b$ initio points carried out with the sURVIBTM code (Ref. 68). An estimate of the mean relative errors in frequencies (goodness of the fit) gives a value of $<5 \%$ for the low $\nu_{i}$ and $<1 \%$ for the two highest $\nu_{i}$.

${ }^{\mathrm{e}}$ References 6, 40.

${ }^{\mathrm{f}}$ Reference 39.

${ }^{\mathrm{g}}$ The $R_{\mathrm{NN}}$ distance was optimized keeping fixed the rest of the geometrical parameters. BE was equal to $3.69 \mathrm{kcal} / \mathrm{mol}$ once the BSSE was included (Ref. 44 ).

${ }^{\mathrm{h}}$ Reference 44.

${ }^{\mathrm{i}}$ Reference 46.

calculations with correlated molecular wave functions of diatomic molecules (e.g., $\mathrm{C}_{2}, \mathrm{~N}_{2}, \mathrm{O}_{2},$. ) with standard-valence cc-pVnZ,-aug-cc-pVnZ (Ref. 77), or core-valence basis sets cc-pCVnZ. ${ }^{78}$ The difficulty of describing dissociation energies of simple diatomic molecules can be illustrated by looking at the most accurate calculations [complete basis set (CBS) limits of full valence CASSCF/IC-MRCI+Q calculations] reported in the abovementioned references; for instance, the relative errors found were $0.9 \%$ and $1.2 \%$ (valence-only CBS limits), or $0.3 \%$ and $0.9 \%$ (all-electron CBS limits) for $\mathrm{N}_{2}$ and $\mathrm{O}_{2}$, respectively.

Spectroscopic constants (i.e., $\nu_{e}, \nu_{e} x_{e}, \alpha_{e}, \overline{D_{e}}, B_{e}$ ) were calculated at the CASPT2 level by fitting 63 computed energies to an extended-Rydberg potential

$$
V(R)=-D_{e}\left(1+\sum_{i=1}^{n=5} a_{i}\left(R-R_{e}\right)^{i}\right) \exp \left(-a_{1}\left(R-R_{e}\right)\right)
$$

In general, a very good agreement with the experimental data was obtained. Again, a clear convergence to the experimental fundamental frequency $\nu_{e}$ is observed when the basis set is improved.

The computed dipole moment at the CASPT2 $(9,7) /$ 6-311G $(2 d)$ level shows an excellent accord with the experimental value. The effects of the dynamic correlation and the active space seem to be very important in contrast to the other computed spectroscopic constants. The calculated mean polarizability $(\bar{\alpha})$ and the anisotropy of polarizability $(\gamma)$

$$
\bar{\alpha}=\frac{1}{3}\left(\alpha_{\|}+2 \alpha_{\perp}\right), \quad \gamma=\left(\alpha_{\|}-\alpha_{\perp}\right),
$$

are less dependent on the dynamic correlation. A much better agreement is found in $\gamma$ than in $\bar{\alpha}$, although a closer value of $\bar{\alpha}$ to the experimental one (nevertheless, only a single experiment is available) ${ }^{76}$ could be expected with larger cc-pVnZ basis sets at the CASPT2 $(9,7)$ level. In fact, a calculation with the CASPT2 $(7,6)$ method at the optimized $\operatorname{CASSCF}(7,6)$ NO distance (i.e., $1.1558 \AA$ ) with an ANO $[14 s 9 p 4 d 3 f / 4 s 3 p 2 d 1 f]$ (Ref. 79) basis set gives much better values: $\alpha=1.702 \AA^{3}$ and $\gamma=0.731 \AA^{3}$. These results seem to support the idea concluded in a previous study of the electric properties of the water molecule in several electronic states ${ }^{71}$ that the CASPT2 method is capable of providing accurate quantitative data for electric properties of atoms and molecules with acceptable small CASSCF reference functions and extended basis sets.

\section{B. Calculated properties of the singlet ground state for the cis- and trans-NO dimers. Trans $\leftrightarrow$ cis isomerization}

Table II displays the calculated properties of the lowest singlet state $\left({ }^{1} A_{1}\right)$ of the cis-NO dimer at different levels of theory, and it is also compared with previous theoretical ( $a b$ 
TABLE III. Experimental data about the cis-NO dimer $\left({ }^{1} A_{1}\right)$.

\begin{tabular}{|c|c|c|c|c|c|c|c|}
\hline Technique & \multicolumn{2}{|c|}{$R_{\mathrm{NN}}(\AA)$} & \multicolumn{2}{|c|}{$R_{\mathrm{NO}}(\AA)$} & \multicolumn{2}{|c|}{$\mathrm{N}_{\mathrm{N}} \mathrm{O}(o)$} & $\begin{array}{c}D_{o} \\
(\mathrm{kcal} / \mathrm{mol})\end{array}$ \\
\hline $\begin{array}{l}\text { FTIR }^{\mathrm{a}} \\
\text { (gas-phase) }\end{array}$ & \multicolumn{2}{|c|}{$2.2630 \pm 0.0012$} & \multicolumn{2}{|c|}{$1.1515 \pm 0.003$} & \multicolumn{2}{|c|}{$97.17 \pm 0.05$} & $\cdots$ \\
\hline $\begin{array}{l}\mathrm{MW}^{\mathrm{b}} \\
\text { (gas-phase) }\end{array}$ & \multicolumn{2}{|c|}{$2.237 \pm 0.002$} & \multicolumn{2}{|c|}{$1.161 \pm 0.006$} & \multicolumn{2}{|c|}{$99.6 \pm 0.4$} & $\cdots$ \\
\hline $\begin{array}{l}\text { MBER }^{\mathrm{c}} \\
\text { (gas-phase) }\end{array}$ & \multicolumn{2}{|c|}{$2.33 \pm 0.12$} & \multicolumn{2}{|c|}{$1.15 \pm 0.01$} & \multicolumn{2}{|l|}{$95 \pm 5$} & $\cdots$ \\
\hline $\begin{array}{l}\text { IR-excitation }+ \\
\text { LIF/sub-Doppler } \\
\text { (gas-phase) }^{\mathrm{d}}\end{array}$ & \multicolumn{2}{|c|}{$\cdots$} & \multicolumn{2}{|c|}{$\cdots$} & \multicolumn{2}{|l|}{$\cdots$} & $2.03 \pm 0.11^{\mathrm{e}}$ \\
\hline $\begin{array}{l}\text { FTIR }^{\mathrm{f}} \\
\text { (gas-phase) }\end{array}$ & \multicolumn{2}{|c|}{$\cdots$} & \multicolumn{2}{|c|}{$\cdots$} & \multicolumn{2}{|l|}{$\cdots$} & $2.18 \pm 0.05$ \\
\hline $\begin{array}{l}\text { IR excitation+ } \\
\text { LIF/sub-Doppler } \\
\text { (gas-phase) }^{\mathrm{g}}\end{array}$ & \multicolumn{2}{|c|}{$\cdots$} & \multicolumn{2}{|c|}{$\ldots$} & \multicolumn{2}{|l|}{$\cdots$} & $2.29 \pm 0.43^{\mathrm{e}}$ \\
\hline $\begin{array}{l}\text { FTIR }^{\text {h }} \\
\text { (gas-phase) }\end{array}$ & \multicolumn{2}{|c|}{$\ldots$} & \multicolumn{2}{|c|}{$\nu_{i}\left(\mathrm{~cm}^{-1}\right)^{\mathrm{j}}$} & \multicolumn{2}{|l|}{$\cdots$} & $1.83 \pm 0.10^{\mathrm{i}}$ \\
\hline Technique & $a_{1}$ & $a_{1}$ & $a_{1}$ & $b_{1}$ & $b_{1}$ & $a_{2}$ & $\begin{array}{c}\mathrm{ZPE}^{\mathrm{k}} \\
(\mathrm{kcal} / \mathrm{mol})\end{array}$ \\
\hline $\begin{array}{l}\text { IR }^{1} \\
\text { (gas-phase) }\end{array}$ & 239.361 & 134.503 & $\cdots$ & 429.140 & $\ldots$ & 117 & $\cdots$ \\
\hline $\begin{array}{l}\text { FTIR }^{\mathrm{a}} \\
\text { (gas-phase) }\end{array}$ & 258.9 & 127.2 & 1868.3 & 430.0 & 1789.2 & 119.2 & 6.57 \\
\hline $\begin{array}{l}\text { RAMAN }^{\mathrm{m}} \\
\text { (solid-phase) }\end{array}$ & 266 & 187 & 1866 & 214 & 1762 & 97 & 6.28 \\
\hline $\begin{array}{l}\text { FTIR }^{\mathrm{n}} \\
\text { (Ar-matrix isolation) }\end{array}$ & 299.3 & 175.4 & 1863.4 & 242.9 & 1776.3 & 103.4 & 6.38 \\
\hline
\end{tabular}

${ }^{\mathrm{a}}$ Reference 4.

${ }^{\mathrm{b}}$ Reference 14 .

${ }^{\mathrm{c}}$ Reference 13.

${ }^{\mathrm{d}}$ Reference 9 .

${ }^{\mathrm{e}}$ The dissociation mainly produces $\mathrm{NO}\left({ }^{2} \Pi_{1 / 2}\right)+\mathrm{NO}\left({ }^{2} \Pi_{3 / 2}\right)$.

${ }^{\mathrm{f}}$ Reference 5.

${ }^{\mathrm{g}}$ Reference 10.

heference 3.

${ }^{\text {i }}$ Value corresponding to $\mathrm{NO}\left({ }^{2} \Pi_{1 / 2}\right)+\mathrm{NO}\left({ }^{2} \Pi_{1 / 2}\right)$.

${ }^{\mathrm{j}}$ Fundamental vibrational frequencies which correspond to: sym. NNO bend, NN str., sym. NO str., asym. NNO bend, asym. NO str., and torsion modes, respectively. The molecule is lying in the $X Z$ plane, with the $z$-axis as the $C_{2}$ axis for the $\left({ }^{14} \mathrm{~N}^{16} \mathrm{O}\right)_{2}$ dimer.

${ }^{\mathrm{k}}$ Zero-point vibrational energy of the dimer.

${ }^{1}$ Reference 6.

${ }^{\mathrm{m}}$ Reference 7.

${ }^{\mathrm{n}}$ Reference 8 .

initio and DFT) studies. Tables III and IV summarize the most relevant experimental data about this dimer and additional theoretical results to be compared with. The CASSCF calculations show a very shallow cis- $(\mathrm{NO})_{2}$ minimum (BE $\approx 0.3 \mathrm{kcal} / \mathrm{mol}$ ) at very long NN distances $(3.1-3.3 \AA)$. We note that the addition of diffuse functions yields the structure with the longest $\mathrm{NN}$ distance both at the $\operatorname{CASSCF}(14,12)$ (i.e., 3.67 ̊) and $\operatorname{CASSCF}(18,14)$ (i.e., $3.34 \AA$ A) levels, decreasing also its corresponding BE. There is a strong influence of the dynamical correlation energy in the description of this minimum as it was pointed out in preceding theoretical studies (e.g., see Refs. 35, 40). In fact, a $\operatorname{CASSCF}(5,5) /$ aug-cc-pVDZ optimization was not able to produce a bound dimer. $^{40}$ The CASPT2 energies, even at the CASSCF optimized geometries, indicate a stable minimum (i.e., $\mathrm{BE} \approx 1.81 \mathrm{kcal} / \mathrm{mol}$ at the CASPT2 $(18,14) / 6-311 \mathrm{G}(2 d)$ level).
Table $\mathrm{V}$ shows the natural orbital occupation numbers at the CASSCF $(18,14)$ level and in Fig. 1 there are depicted the shapes of the MOs. The $\pi_{2 p}^{*}$ electron of each NO monomer is distributed between a $\sigma$ bonding MO (the 4th $a_{1}$ ) and a $\sigma^{*}$ antibonding MO (the 4th $b_{1}$ ). Although the values for the MOs corresponding to the nitrogen $2 s$ lone pairs $\left(a_{1}\right.$ and $b_{1} \sigma_{\mathrm{LP}}$ nonbonding MOs) are quite close to 2 , which is the value assumed at the $\operatorname{CASSCF}(14,12)$ level, several important changes are appreciated when the highest active space is used. Thus, in spite of the small change in the CASSCF energies, an important shift is produced in the NN distance (i.e., $R_{\mathrm{NN}}$ goes from 3.3108 to $3.0623 \AA$ ). Moreover, at the CASPT2 level both the BE and the NN distance are also significantly modified (i.e., $R_{\mathrm{NN}}$ goes from 2.3428 to 2.3271 $\AA$ ). On the other hand, in a study in progress about other high energy symmetrical ONNO minima and several transition states involved in the reaction 
TABLE IV. Properties of the cis-NO $\operatorname{dimer}\left({ }^{1} A_{1}\right)$ at various levels of theory at the CASPT2 $(18,14) / 6-311 \mathrm{G}(2 d)$ optimum geometry.

\begin{tabular}{|c|c|c|c|}
\hline Method & $\begin{array}{l}\text { Energy } \\
(\mathrm{H})\end{array}$ & $\begin{array}{l}\mu_{e} \\
\text { (D) }\end{array}$ & $\begin{array}{c}\mathrm{BE}^{\mathrm{a}} \\
(\mathrm{kcal} / \mathrm{mol})\end{array}$ \\
\hline \multicolumn{4}{|l|}{ CASPT2 $(18,14):$} \\
\hline$/ 6-311 \mathrm{G}(2 d)$ & -259.396920 & 0.2239 & $4.31(2.53)$ \\
\hline$/ 6-311+\mathrm{G}(2 d)$ & -259.406569 & 0.1831 & $4.04(2.94)$ \\
\hline /cc-pVDZ & -259.190276 & 0.1505 & $3.98(1.06)$ \\
\hline /cc-pVTZ & -259.463724 & 0.1932 & $4.34(3.17)$ \\
\hline /aug-cc-pVTZ & -259.507708 & 0.1798 & $6.31(4.58)$ \\
\hline /cc-pVQZ & -259.629724 & 0.1786 & $5.00(4.32)$ \\
\hline $\operatorname{MRCI}(6)+Q^{b}$ & -259.321843 & 0.1683 & 2.34 \\
\hline \multicolumn{4}{|l|}{$/ 6-311 \mathrm{G}(2 d)$} \\
\hline $\operatorname{MRCI}(10)+\mathrm{Q}^{\mathrm{b}}$ & -259.329024 & 0.1611 & 3.66 \\
\hline \multicolumn{4}{|l|}{$/ 6-311 \mathrm{G}(2 d)$} \\
\hline /cc-pVTZ & -259.418382 & 0.1290 & 3.46 \\
\hline Experimental $^{\mathrm{c}}$ & $\ldots$ & 0.171 & $3.1 \pm 0.3^{d}$ \\
\hline
\end{tabular}

${ }^{\mathrm{a} B i n d i n g}$ energy $\left(D_{e}\right)$ with respect to $\mathrm{NO}+\mathrm{NO}$ at $20 \AA$. The $\mathrm{BE}_{\mathrm{CP}}$ energies are given in parentheses.

${ }^{b}$ MRCI-SD $+Q$ with CASSCF $(18,14)$ molecular orbitals and all 22 valence $e$ - correlated. The number of CSFs (in $C_{2 v}$ symmetry) were equal to 1043446 and 2106468 for the two MRCI calculations, respectively. ${ }^{\mathrm{c}}$ Reference 13 .

${ }^{\mathrm{d}}$ The experimental value is derived from the data reported in Table III.

$$
\begin{aligned}
& \mathrm{O}\left({ }^{1} D\right)+\mathrm{N}_{2} \mathrm{O}\left(X^{1} \Sigma^{+}\right) \\
& \rightarrow \mathrm{NO}\left({ }^{2} \Pi\right)+\mathrm{NO}\left({ }^{2} \Pi\right) \Delta \mathrm{H}_{298 \mathrm{~K}}^{\circ}=-81.4 \mathrm{kcal} \cdot \mathrm{mol}^{-1},
\end{aligned}
$$

we have also observed ${ }^{80}$ that the largest active space is necessary to get a correct description of this reaction. Moreover, experimental studies on the $\mathrm{NO}\left(v^{\prime}\right)$ vibrational distributions $^{81}$ and on the scalar and vector properties of the $\mathrm{NO}\left(v^{\prime}=0\right)$ (Ref. 82) produced in this reaction stress the influence of the NO-dimers on the dynamics of this reaction. Therefore, this active space will be the space mainly used throughout this study.

The optimized structure and the harmonic frequencies of the cis-NO dimer were determined by means of an analytical fit of 59 CASPT2 $(18,14) / 6-311 \mathrm{G}(2 d)$ points. The optimum geometry compares very well with old experimental results, ${ }^{13}$ and differs a bit more in the NN distance derived in a more recent experimental study. ${ }^{4}$ The inclusion of the BSSE energy correction in a partial optimization of the NN distance produces a curve (see Fig. 2) than can be fitted by means of an exp-6 curve, ${ }^{1}$

$$
V(R)=A \exp (-B \cdot R)-\frac{C}{R^{6}}
$$

which furnishes a longer value $\left(R_{\mathrm{NN}}=2.3678 \AA\right)$ as could be expected (e.g., in water dimer the BSSE effect produces a lengthening of the OO distance from $2.931 \AA$ to $3.034 \AA$ at the MP4SDQ(full)/D95 ++ $(d, p)$ (Ref. 83) in comparison with an experimental value of $2.946 \AA$ ).

The calculated binding energy has a value close to the most accurate previous ab initio studies, ${ }^{39,44}$ and gives better results than the previous DFT studies. ${ }^{44,46}$ The CP-corrected

\begin{tabular}{|c|c|c|c|c|c|c|c|c|c|c|c|c|c|c|c|c|c|}
\hline $\begin{array}{l}c i s-(\mathrm{NO}) \\
C_{2 v}-\left({ }^{1} A_{1}\right.\end{array}$ & & $\begin{array}{c}a_{1} \\
\left(\sigma_{\mathrm{LP}}\right)\end{array}$ & $\begin{array}{l}a_{1} \\
(\sigma)\end{array}$ & $\begin{array}{l}a_{1} \\
(\sigma)\end{array}$ & $\begin{array}{l}a_{1} \\
(\sigma)\end{array}$ & $\begin{array}{l}a_{1} \\
(\sigma)\end{array}$ & $\begin{array}{l}a_{2} \\
(\pi)\end{array}$ & $\begin{array}{l}a_{2} \\
(\pi)\end{array}$ & $\begin{array}{c}b_{1} \\
\left(\sigma_{\mathrm{LP}}\right)\end{array}$ & $\begin{array}{l}b_{1} \\
(\sigma)\end{array}$ & $\begin{array}{l}b_{1} \\
(\sigma)\end{array}$ & $\begin{array}{l}b_{1} \\
(\sigma)\end{array}$ & $\begin{array}{l}b_{1} \\
(\sigma)\end{array}$ & $\begin{array}{l}b_{2} \\
(\pi)\end{array}$ & $\begin{array}{l}b_{2} \\
(\pi)\end{array}$ & Coef. & $\begin{array}{c}\text { Ref. } \\
\text { weight: }\end{array}$ \\
\hline \multirow[t]{6}{*}{ CFSs: } & 1 & 2 & 2 & 2 & 2 & 0 & 2 & 0 & 2 & 2 & 2 & 0 & 0 & 2 & 0 & 0.82 & \\
\hline & 2 & 2 & 2 & 2 & 0 & 0 & 2 & 0 & 2 & 2 & 2 & 2 & 0 & 2 & 0 & -0.44 & \\
\hline & 3 & 2 & 2 & 2 & 2 & 0 & $u$ & $u$ & 2 & 2 & 2 & 0 & 0 & $d$ & $d$ & 0.11 & \\
\hline & 4 & 2 & 2 & 2 & 2 & 0 & $u$ & $d$ & 2 & 2 & $u$ & $d$ & 0 & 2 & 0 & -0.067 & \\
\hline & 5 & 2 & 2 & 2 & 2 & 0 & 2 & 0 & 2 & 2 & $u$ & $d$ & 0 & $u$ & $d$ & -0.066 & \\
\hline & 6 & 2 & 2 & 2 & 0 & 0 & $u$ & $u$ & 2 & 2 & 2 & 2 & 0 & $d$ & $d$ & -0.057 & \\
\hline \multicolumn{2}{|c|}{ n. occupation } & 1.993 & 1.980 & 1.974 & 1.559 & 0.028 & 1.925 & 0.079 & 1.992 & 1.975 & 1.972 & 0.488 & 0.028 & 1.928 & 0.081 & & 0.885 \\
\hline \multicolumn{2}{|c|}{$\begin{array}{r}\text { trans-(NO) })_{2} \\
\quad C_{2 h-\left({ }^{1} A_{g}\right)}\end{array}$} & $\begin{array}{c}a_{g} \\
\left(\sigma_{\mathrm{LP}}\right)\end{array}$ & $\begin{array}{l}a_{g} \\
(\sigma)\end{array}$ & $\begin{array}{l}a_{g} \\
(\sigma)\end{array}$ & $\begin{array}{l}a_{g} \\
(\sigma)\end{array}$ & $\begin{array}{l}a_{g} \\
(\sigma)\end{array}$ & $\begin{array}{l}b_{g} \\
(\pi)\end{array}$ & $\begin{array}{l}b_{g} \\
(\pi)\end{array}$ & $\begin{array}{c}b_{u} \\
\left(\sigma_{\mathrm{LP}}\right)\end{array}$ & $\begin{array}{l}b_{u} \\
(\sigma)\end{array}$ & $\begin{array}{l}b_{u} \\
(\sigma)\end{array}$ & $\begin{array}{l}b_{u} \\
(\sigma)\end{array}$ & $\begin{array}{l}b_{u} \\
(\sigma)\end{array}$ & $\begin{array}{l}a_{u} \\
(\pi)\end{array}$ & $\begin{array}{l}a_{u} \\
(\pi)\end{array}$ & Coef. & $\begin{array}{c}\text { Ref. } \\
\text { weight: }\end{array}$ \\
\hline \multirow[t]{6}{*}{ CFSs: } & 1 & 2 & 2 & 2 & 2 & 0 & 2 & 0 & 2 & 2 & 2 & 0 & 0 & 2 & 0 & 0.74 & \\
\hline & 2 & 2 & 2 & 2 & 0 & 0 & 2 & 0 & 2 & 2 & 2 & 2 & 0 & 2 & 0 & -0.57 & \\
\hline & 3 & 2 & 2 & 2 & 2 & 0 & $u$ & $u$ & 2 & 2 & 2 & 0 & 0 & $d$ & $d$ & -0.097 & \\
\hline & 4 & 2 & 2 & 2 & 0 & 0 & $u$ & $u$ & 2 & 2 & 2 & 2 & 0 & $d$ & $d$ & 0.074 & \\
\hline & 5 & 2 & 2 & 2 & 2 & 0 & 2 & 0 & 2 & 2 & $u$ & $d$ & 0 & $u$ & $d$ & 0.063 & \\
\hline & 6 & 2 & 2 & 2 & 2 & 0 & $u$ & $d$ & 2 & 2 & $u$ & $d$ & 0 & 2 & 0 & -0.063 & \\
\hline \multicolumn{2}{|c|}{ n. occupation } & 1.993 & 1.977 & 1.974 & 1.264 & 0.028 & 1.926 & 0.080 & 1.992 & 1.974 & 1.976 & 0.782 & 0.028 & 1.926 & 0.081 & & 0.888 \\
\hline \multicolumn{2}{|c|}{$\begin{array}{c}\mathrm{TS}-(\mathrm{NO})_{2} \\
C_{2}-\left({ }^{1} A\right)\end{array}$} & $a$ & $a$ & $a$ & $a$ & $a$ & $a$ & $a$ & $b$ & $b$ & $b$ & $b$ & $b$ & $b$ & $b$ & Coef. & $\begin{array}{c}\text { Ref. } \\
\text { weight: }\end{array}$ \\
\hline \multirow[t]{6}{*}{ CFSs: } & 1 & 2 & 2 & 2 & 2 & 0 & 2 & 0 & 2 & 2 & 2 & 0 & 0 & 2 & 0 & 0.71 & \\
\hline & 2 & 2 & 2 & 2 & 0 & 0 & 2 & 0 & 2 & 2 & 2 & 2 & 0 & 2 & 0 & -0.60 & \\
\hline & 3 & 2 & 2 & 2 & 2 & 0 & $u$ & $u$ & 2 & 2 & 2 & 0 & 0 & $d$ & $d$ & 0.094 & \\
\hline & 4 & 2 & $u$ & 2 & 2 & 0 & 2 & $u$ & 2 & 2 & 2 & $d$ & 0 & $d$ & 0 & 0.062 & \\
\hline & 5 & 2 & 2 & 2 & 0 & 0 & $u$ & $u$ & 2 & 2 & 2 & 2 & 0 & $d$ & $d$ & -0.078 & \\
\hline & 6 & 2 & 2 & 2 & 2 & 0 & $u$ & $d$ & 2 & 2 & $u$ & $d$ & 0 & 2 & 0 & -0.062 & \\
\hline \multicolumn{2}{|c|}{ n. occupation } & 1.993 & 1.977 & 1.974 & 1.185 & 0.028 & 1.927 & 0.080 & 1.992 & 1.974 & 1.976 & 0.861 & 0.028 & 1.926 & 0.080 & & 0.888 \\
\hline
\end{tabular}

TABLE V. Natural orbital occupation numbers and the most important CSFs in the CASSCF $(18,14)$ wave function, and the reference weight in the CASPT2 $(18,14)$ wave function of all stationary points with the $6-311 \mathrm{G}(2 d)$ basis set. 

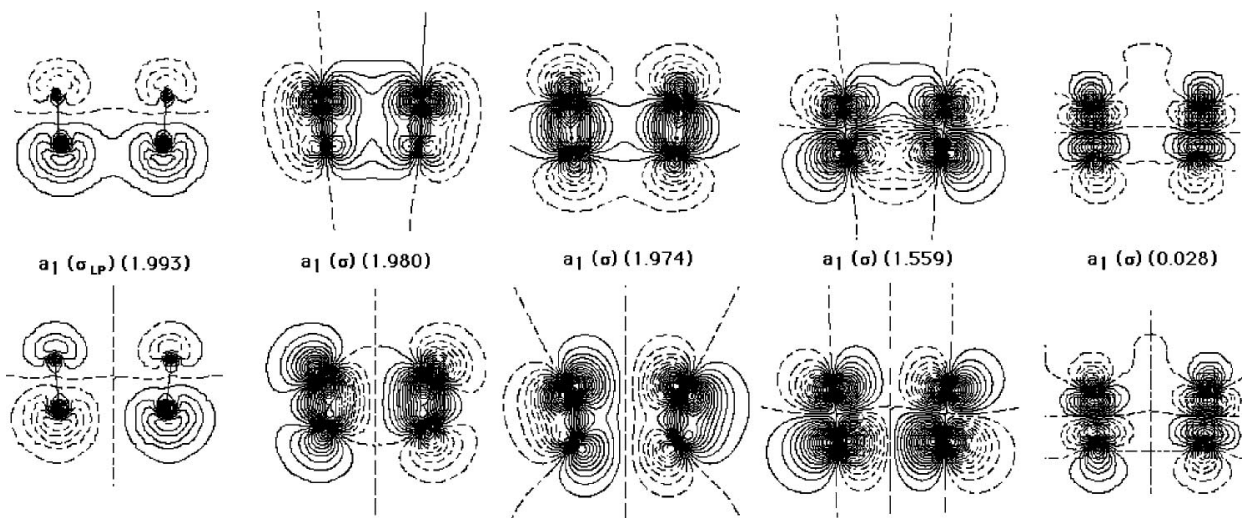

$b_{1}\left(\sigma_{L P}\right)(1.992)$

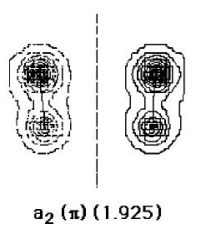

$b_{1}(\sigma)(1.975)$

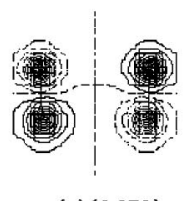

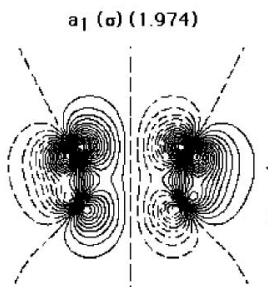

$b_{1}(\sigma)(1.972)$

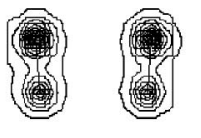

$b_{2}(\pi)(1.928)$

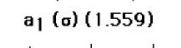

$a_{1}(0)(0.028)$

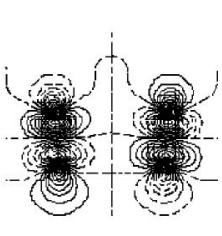

$b_{1}(\sigma)(0.028)$
FIG. 1. Contour plots of the 14 active molecular orbitals calculated at the CASPT2 $(18,14) / 6-311 \mathrm{G}(2 d)$ . $C_{2 v}$ optimum geometry and distributed according to their irreducible representation. The natural orbital occupation numbers and $\sigma-\pi$ symmetry with respect to the molecular plane of the dimer are also indicated. $\pi$ orbitals are given relative to a plane parallel to the molecular one and shifted to the same height above it. binding energy (Table IV) (i.e., $\mathrm{BE}_{\mathrm{CP}}=2.53 \mathrm{kcal} / \mathrm{mol}$ at the CASPT2 $(18,14) / 6-311 \mathrm{G}(2 d)$ level) agrees well with the experimental value (i.e., $3.1 \pm 0.3 \mathrm{kcal} / \mathrm{mol}$, see Table III) and lies within the accuracy of this method (e.g., 7.4\% of relative error in the $D_{e}$ of NO molecule). A study of the basis set effect in the BE, BSSE, and the electric dipole moment is presented in Table IV along with several MRCI calculations. The MRCI reference spaces were chosen so that a balanced description of both the cis-NO dimer and the two NO molecules at a large internuclear distance was obtained, that is, the CSFs with the greatest weights either at the dimer or at the 2 NO supermolecule CASSCF calculations were included. The two reference spaces can be related in a direct way to the main CSFs in the previous $\operatorname{CASSCF}(18,14)$ calculations, which are tabulated in Table V. The first reference space, comprising six CSFs, derives from the configurations corresponding to CSFs number 1, 2, 3, and 6. Analogously, the second reference space includes the ten CSFs which derive from the parent configurations corresponding to all the six main CSFs in Table V; each one of the 3, 4, 5, and 6 CSFs have another counterpart CSF. The reference CSFs accounted for approximately $87 \%$ of the wave function in a similar way as in the CASPT2 calculations (ca. 88\%) (Table V).

As can be seen in Table IV, the 6-311G+ $(2 d)$ basis set and several correlation-consistent Dunning's basis sets have been used, apart from the 6-311G $(2 d)$ basis set, in the calculation of the $\mathrm{BE}$ and $\mathrm{BE}_{\mathrm{CP}}$ energies at the CASPT2 $(18,14)$ level. The geometries of the monomer and dimer have been kept fixed at their CASPT2 $(18,14) / 6-311 \mathrm{G}(2 d)$ values. The calculated BE values slightly overestimate the experimental value of the cis-NO dimer in all cases, the result with the cc-pVDZ basis set being the nearest to the experimental one. As refers to the $\mathrm{BE}_{\mathrm{CP}}$, the $\mathrm{BSSE}$ correction shifts the energies to the correct values, and the best result is the one obtained with the cc-pVTZ basis, which lies within the bounds of the experimental value and is also very similar to the
6-311G $(2 d)$ and $6-311 \mathrm{G}+(2 d)$ results. The magnitude of the BSSE energy is remarkable with values that range from around $73 \%$ (cc-pVDZ) to around 14\% (cc-pVQZ) of the $\mathrm{BE}$. It is also evident that a limit value of the three properties, $\mathrm{BE}, \mathrm{BSSE}$, and $\mathrm{BE}_{\mathrm{CP}}$ would be obtained by increasing the size of the cc-pVnZ basis, although the function describing this dependence may not be the same in all cases. The

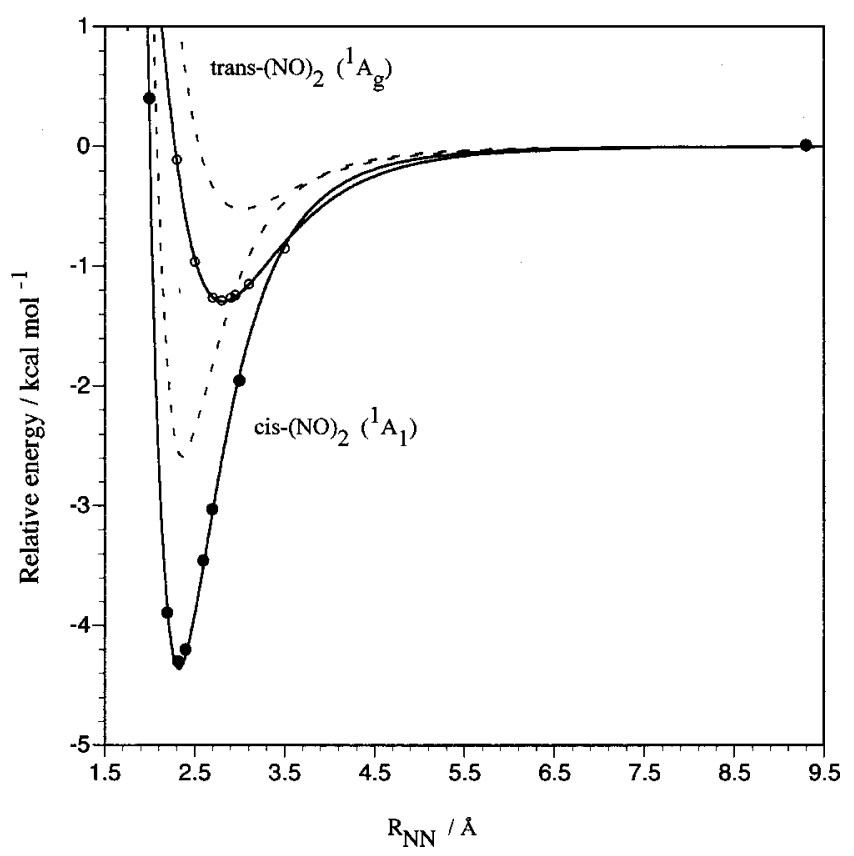

FIG. 2. A $b$ initio CASSCF/CASPT2(18/14)/6-311G(2d) curves of the energy of the cis- and trans-NO dimers in their lowest singlet states as a function of the $\mathrm{NN}$ distance. The NO distances and the NNO angles are kept fixed at their optimal values: $\operatorname{cis}-(\mathrm{NO})_{2}, R_{\mathrm{NO}}=1.1594 \AA$ and $\angle \mathrm{NNO}$ $=94.5^{\circ}$ and $\bigcirc$ trans $-\left(\mathrm{NO}_{2}\right), R_{\mathrm{NO}}=1.1594 \AA$ and $\angle \mathrm{NNO}=109.1^{\circ}$. Curves represent an analytical fit by means of an exp-6 curve [Eq. (15)]: solid line (without BSSE) and dashed line (with BSSE). 
TABLE VI. Properties of the optimized trans-NO dimer $\left({ }^{1} A_{g}\right)$ and the cis $\leftrightarrow$ trans transition state $\left({ }^{1} A\right)$ at various levels of theory.

\begin{tabular}{|c|c|c|c|c|c|c|c|c|c|c|c|c|c|c|}
\hline \multirow[b]{2}{*}{ Method } & \multirow{2}{*}{$\begin{array}{l}\text { Energy } \\
(\mathrm{H})\end{array}$} & \multirow{2}{*}{$\begin{array}{l}R_{\mathrm{NN}} \\
(\AA)\end{array}$} & \multirow{2}{*}{$\begin{array}{l}R_{\mathrm{NO}} \\
(\AA)\end{array}$} & \multirow{2}{*}{$\begin{array}{c}\mathrm{N}_{\mathrm{N}} \mathrm{O} \\
(o)\end{array}$} & \multirow{2}{*}{$\begin{array}{c}\mathrm{ON}_{\mathrm{N}} \mathrm{O} \\
(o)\end{array}$} & \multirow{2}{*}{$\begin{array}{l}\mu_{e} \\
\text { (D) }\end{array}$} & \multirow{2}{*}{$\begin{array}{c}\mathrm{BE}^{\mathrm{a}} \\
(\mathrm{kcal} / \mathrm{mol})\end{array}$} & \multirow{2}{*}{$\begin{array}{c}\Delta \mathrm{ZPE}^{\mathrm{b}} \\
(\mathrm{kcal} / \mathrm{mol})\end{array}$} & \multicolumn{6}{|c|}{$\nu_{1}\left(\mathrm{~cm}^{-1}\right)^{\mathrm{c}}$} \\
\hline & & & & & & & & & $a_{g}$ & $a_{g}$ & $a_{g}$ & $b_{u}$ & $b_{u}$ & $a_{u}$ \\
\hline $\begin{array}{l}\text { trans-(NO) } \\
C_{2 h}-\left({ }^{1} A_{g}\right)\end{array}$ & & & & & & & & & & & & & & \\
\hline $\begin{array}{l}\text { CASSCF }(18,14) \\
/ 6-311 \mathrm{G}(2 d)\end{array}$ & -258.795700 & 3.5403 & 1.1604 & 109.1 & 180.0 & 0 & 0.20 & 0.24 & 64.0 & 27.9 & 1878.0 & 26.6 & 1877.7 & 45.4 \\
\hline $\begin{array}{l}\operatorname{CASPT} 2(18,14) \\
/ 6-311 \mathrm{G}(2 d)^{\mathrm{d}}\end{array}$ & -259.392092 & 2.7754 & 1.1594 & 109.1 & 180.0 & 0 & $1.28(0.42)$ & 0.53 & 204.9 & 62.6 & 1852.1 & 62.4 & 1841.1 & 48.6 \\
\hline $\begin{array}{l}\text { CASPT2D(14,12) } \\
/ \text { ANO }[5 s 4 p 3 d 2 f]^{\mathrm{e}, \mathrm{f}}\end{array}$ & -259.48584 & 2.70 & 1.152 & 108.6 & 180.0 & 0 & 1.61 & $\cdots$ & $\cdots$ & $\cdots$ & $\cdots$ & $\cdots$ & $\cdots$ & $\cdots$ \\
\hline $\begin{array}{l}\text { DFT-B3LYP } \\
/ 6-311 \mathrm{G}+(d)^{\mathrm{f}}\end{array}$ & -259.85271 & 1.871 & 1.155 & 108.6 & 180.0 & 0 & -6.69 & $\cdots$ & 277 & 796 & 1901 & 260 & 1783 & 79 \\
\hline $\begin{array}{l}\text { DFT-PLAP1 XC } \\
/ 6-311 \mathrm{G}+(d)^{\mathrm{g}}\end{array}$ & $\cdots$ & 2.071 & 1.163 & 109.6 & 180.0 & 0 & $5.03(4.63)$ & $\cdots$ & $\cdots$ & $\cdots$ & $\cdots$ & $\cdots$ & $\cdots$ & $\cdots$ \\
\hline $\begin{array}{l}\text { TS-(NO) })_{2} \\
C_{2}-\left({ }^{1} A\right)\end{array}$ & & & & & & & & & a & $\mathrm{a}$ & a & $\mathrm{b}$ & $\mathrm{b}$ & a \\
\hline $\begin{array}{l}\text { CASSCF }(18,14) \\
/ 6-311 \mathrm{G}(2 d)^{\mathrm{h}}\end{array}$ & -258.795603 & 3.5293 & 1.1606 & 91.0 & 57.8 & 0.3054 & -0.061 & -0.037 & 22.7 & 51.6 & 1890.3 & 39.5 & 1889.4 & $19.9 i$ \\
\hline $\begin{array}{l}\text { CASPT2 }(18,14) \\
/ 6-311 \mathrm{G}(2 d)^{\mathrm{d}}\end{array}$ & -259.391623 & 2.9596 & 1.1590 & 101.1 & 113.7 & 0.1335 & -0.29 & -0.13 & 179.6 & 48.3 & 1824.5 & 111.2 & 1814.8 & $129.1 i$ \\
\hline
\end{tabular}

a Binding energy with respect to $\mathrm{NO}+\mathrm{NO}$ at $20 \AA$ for trans-NO dimer and respect to trans-NO dimer for TS. The BE-BSSE energies are given in parentheses. ${ }^{\mathrm{b}}$ Difference of calculated zero-point vibrational energy between the trans-NO dimer and the NO+NO asymptotic energy (including $\nu_{e} x_{e}$ when available) or between the TS and the trans-NO dimer.

${ }^{\mathrm{c}}$ Masses of the most abundant isotopes $\left({ }^{14} \mathrm{~N}\right.$ and $\left.{ }^{16} \mathrm{O}\right)$ are used in the calculation of the harmonic vibrational frequencies which correspond to: sym. NNO bend, NN str., sym. NO str., asym. NNO bend, asym. NO str. and torsion modes, respectively. The $z$-axis is the $C_{2}$ axis. In $C_{2}$ point group the irreducible representations become $a$ and $b$ class.

${ }^{\mathrm{d}}$ Harmonic frequencies and geometry derived with a lower active space $(14,12)$ by means of an analytical fit of $45\left(C_{2 h}\right.$ minimum) and $62\left(C_{2}\right.$ TS) ab initio points, carried out with the SURVIBTM code ${ }^{68}$. An estimate of the mean relative errors in frequencies (goodness of the fit) gives a value of $<7 \%$ for the low $\nu_{i}$ and $<1 \%$ for the two highest $\nu_{i}$.

${ }^{\mathrm{e}}$ The $R_{\mathrm{NN}}$ distance was optimized keeping fixed the rest of the geometrical parameters. BE was equal to $0.92 \mathrm{kcal} / \mathrm{mol}$ once the BSSE was included.

${ }^{\mathrm{f}}$ Reference 44.

${ }^{\mathrm{g}}$ Reference 46.

${ }^{\mathrm{h}}$ Harmonic frequencies calculated with a lower active space $(14,12)$.

CASPT2 with the G2 correction tends to overestimate the $\mathrm{BE}_{\mathrm{CP}}$ value in the valence-only CBS limit. The increase of the basis set with more diffuse functions tends to describe better the $\mathrm{BE}$ in one case [i.e., 6-311G+ $(2 d)]$ but augment too much the BE in the other case (i.e., aug-cc-pVTZ). As concerns the MRCI results, the BE shows in general a better agreement with the experimental value than for the CASPT2 level, although no correction for the BSSE has been obtained. The values are rather stable with respect to the size of the MRCI space and to the basis set employed.

The values predicted for the dipole moment oscillate, although the best results are obtained with the largest basis sets or with those including diffuse functions as could be expected. The value calculated at the CASPT2 $(18,14) / \mathrm{cc}-$ pVQZ level $(0.1786 \mathrm{D})$ differs only by $4.4 \%$ from the experimental value. Nevertheless, to our knowledge there is only one experimental measure for this magnitude without a reported error bar. In the literature there are very few calculations of $\mu_{e}$ for the singlet state of the cis-NO dimer which compare much worse than that reported in this work. Thus, several DFT calculations give values ranging from 0.092 to $0.163 \mathrm{D},{ }^{41,46}$ and a recent MRCI-SD/cc-pVTZ study gives a value of $0.238 \mathrm{D}^{40}$

The CASSCF calculated low harmonic frequencies $\left(\nu_{1}\right.$, $\nu_{2}, \nu_{4}$, and $\nu_{6}$ ) disagree with the experimental ones due to the incorrect geometry predicted at this level. Nevertheless, the CASPT2 $(18,14) / 6-311 \mathrm{G}(2 d)$ values show an excellent accord with the gas-phase experimental values. ${ }^{4,6}$ In fact, there is a dispersion of the experimental low frequencies as it is summarized in Table III, possibly originated by the environmental perturbations produced in condensed phases over this weak dimer. ${ }^{6}$ The calculated values improve all previous $a b$ initio or DFT results as can be seen in Tables II and III. The calculated torsion $a_{2}$ frequency presents the highest separation with respect to the experimental values. Our estimate of a mean relative error of about $5 \%$ in its derivation does not explain this difference. However, the description of this mode possibly would require the calculation of a larger number of $a b$ initio points (which is very CPU demanding), in $C_{1}$ and $C_{2}$ symmetries, than the value finally used in our estimate. Moreover, an enhancement could also be expected by using Dunning's cc-pVnZ basis sets with the CASPT2 method, although in a previous $\operatorname{CCSD}(\mathrm{T})$ /aug-cc-pVDZ calculation $^{6,40}$ almost the same value (i.e., $190.2 \mathrm{~cm}^{-1}$ ) was obtained.

Table VI displays the calculated properties of the lowest singlet state $\left({ }^{1} A_{g}\right)$ of the trans-NO dimer. A similar behavior as for the cis-NO dimer is found when CASSCF and CASPT2 optimum geometries are compared. In particular, the results with the $6-311 \mathrm{G}+(2 d)$ basis set are worse than those obtained with the $6-311 \mathrm{G}(2 d)$ one. The minimum is 
TABLE VII. Parameters of the ab initio CASSCF/CASPT2(18/14)/6-311G(2d) fittings performed in Figs. 1-3 by means of an exp-6 curve (Eq. 15). For each dimer, the second row shows the parameters for the BSSE corrected curves $\left(\mathrm{BE}_{\mathrm{CP}}\right)$.

\begin{tabular}{cccccc}
\hline \hline \multirow{2}{*}{ Dimer } & $\begin{array}{c}A \\
\left(\mathrm{kcal} \cdot \mathrm{mol}^{-1}\right)\end{array}$ & $\begin{array}{c}B \\
\left(\AA^{-1}\right)\end{array}$ & $\begin{array}{c}C \\
\left(\mathrm{kcal} \cdot \mathrm{mol}^{-1} \cdot \AA^{-6}\right)\end{array}$ & $\begin{array}{c}R_{\mathrm{NN}} \\
(\AA)\end{array}$ & $\begin{array}{c}\mathrm{BE} \\
\left(\mathrm{kcal} \cdot \mathrm{mol}^{-1}\right)\end{array}$ \\
\hline \multirow{2}{*}{ cis- $(\mathrm{NO})_{2}\left({ }^{1} A_{1}\right)$} & $1.489 \times 10^{4}$ & 3.003 & $2.223 \times 10^{3}$ & 2.3304 & 4.30 \\
& $6.708 \times 10^{5}$ & 5.312 & $8.547 \times 10^{2}$ & 2.3678 & 2.54 \\
cis- $(\mathrm{NO})_{2}\left({ }^{3} B_{2}\right)$ & $5.123 \times 10^{4}$ & 3.506 & $1.794 \times 10^{3}$ & 2.9885 & 1.08 \\
& $4.405 \times 10^{4}$ & 3.627 & $7.277 \times 10^{2}$ & 3.2920 & 0.28 \\
trans- $(\mathrm{NO})_{2}\left({ }^{1} A_{g}\right)$ & $2.171 \times 10^{5}$ & 4.528 & $1.597 \times 10^{3}$ & 2.8165 & 1.29 \\
& $1.096 \times 10^{4}$ & 3.112 & $1.083 \times 10^{3}$ & 3.0168 & 0.52 \\
trans- $(\mathrm{NO})_{2}\left({ }^{3} A_{u}\right)$ & $2.280 \times 10^{4}$ & 3.179 & $1.942 \times 10^{3}$ & 2.9764 & 1.02 \\
& $3.535 \times 10^{4}$ & 3.615 & $7.284 \times 10^{2}$ & 3.1636 & 0.35 \\
\hline \hline
\end{tabular}

barely stable and the NN distance extremely long (i.e., 4.26 $\AA)$ at the $\operatorname{CASSCF}(18,14)$ level. A much longer NN distance is found for the trans-NO dimer [i.e., 2.7754 $\AA$ with a grid of 45 CASPT2 $(14,12) / 6-311 \mathrm{G}(2 d)$ points] than for the cis-NO one. The BSSE correction lengthens the NN distance to approximately $3.0168 \AA$ (Table VII and Fig. 2). The present results differ from the shorter NN DFT distances ${ }^{44,46}$ and agree with previous ab initio studies ${ }^{44}$ Comparing the $\mathrm{NN}$ distance, which is the most relevant geometrical parameter for the cis-and trans-NO dimers, it is observed that ab initio UMP2 (Ref. 42) and DFT (Refs. 44-46) studies always yield an NN distance shorter for the trans-NO dimer, in an opposite behavior to the multiconfigurational $a b$ initio results obtained in the present work or in Ref. 44. It is possible that an accurate and complete description of the main properties of these dimers cannot be obtained with monoreference $a b$ initio or standard DFT methods. Regarding the rest of geometrical parameters (i.e., $R_{\mathrm{NO}}$ and $<\mathrm{NNO}$ ), similar values were found in all studies for the trans-NO dimer. The calculated $\mathrm{BE}$ shows that the trans-NO dimer is much less stable than the cis-NO dimer (i.e., $3.03 \mathrm{kcal} / \mathrm{mol}$ at the CASPT2 $(18,14) / 6-311 \mathrm{G}(2 d)$ level and $2.01 \mathrm{kcal} / \mathrm{mol}$ including the BSSE corrections with respect to the cis-NO dimer) in agreement with previous DFT studies, whose values range from 3.15 to $5.45 \mathrm{kcal} / \mathrm{mol}$ (Ref. 45) or from 2.92 to 4.72 $\mathrm{kcal} / \mathrm{mol}^{46}$

Comparison with anionic or cationic NO dimers such as $(\mathrm{NO})_{2}^{-}$and $(\mathrm{NO})_{2}^{+}$species in planar cis and trans structures, indicates an opposite behavior in their stability and in their NN distance. The trans- and cis- $(\mathrm{NO})_{2}^{+}$species have $\mathrm{NN}$ distances equal to 2.2549 and $2.2774 \AA$ at the UQCISD/6-311+G(3df) level, respectively, and the transspecies is $0.29 \mathrm{kcal} / \mathrm{mol}$ more stable than the cis one at the RCCSD(T)/aug-cc-pVQZ (no $g$ ) level at the indicated geometries. ${ }^{84}$ The trans- and cis- $(\mathrm{NO})_{2}^{-}$species present $\mathrm{NN}$ distances equal to 1.264 and $1.292 \AA$ at the B3LYP/6-311G $+(d)$ level, respectively, and the trans species is $3.00 \mathrm{kcal} / \mathrm{mol}$ more stable than the cis one at the CASPT2D $(15,12) / A N O[5 s 4 p 3 d 2 f]$ level at the indicated geometries. ${ }^{44}$

A value of only $0.42 \mathrm{kcal} / \mathrm{mol}$ is obtained for the $\mathrm{BE}_{\mathrm{CP}}$ of the trans-NO dimer at the CASPT2 $(18,14) / 6-311 \mathrm{G}(2 d)$ level. The inclusion of the calculated $\triangle \mathrm{ZPE}$ correction (i.e., $0.53 \mathrm{kcal} / \mathrm{mol}$ ) indicates that this trans-NO dimer should be almost unbound, which agrees with the difficulty to get any experimental information about this dimer.

The harmonic frequencies obtained for the trans-NO dimer are shown in Table VI. Unfortunately, the only piece of experimental information indicative of its structure is the value for the $b_{u}$ asymmetric NO stretching mode $\left(\nu_{5}\right)$ of $1747.1 \mathrm{~cm}^{-1}$ (Ref. 8) (in Ar matrix), $1759.57 \mathrm{~cm}^{-1}$ (Refs. 14,85 ) (in nitrogen matrix), or $1764 \mathrm{~cm}^{-1}$ (Ref. 86) (in nitrogen matrix), which is not so far from the CASPT2 $(18,14) / 6-311 \mathrm{G}(2 d)$ one, $1841.1 \mathrm{~cm}^{-1}$. Legay et al. ${ }^{85}$ have also assigned an IR $1861.12 \mathrm{~cm}^{-1}$ peak to the symmetric NO stretching mode $\left(\nu_{3}\right)$ that becomes active under a strong cage effect in nitrogen matrices. The calculated CASPT2 $(18,14) / 6-311 \mathrm{G}(2 d)$ value, $1852.1 \mathrm{~cm}^{-1}$, compares much better with this experimental one. Nevertheless, it could be expected slightly higher experimental frequencies in gas-phase than in isolated matrices, in a similar way as it was found for the cis-NO dimer (Table III), possibly giving an even better agreement with the $\nu_{5}$ calculated value. The values of the lower normal mode frequencies, $\nu_{1}, \nu_{2}, \nu_{4}$, and $\nu_{6}$ are even smaller than those obtained for the cisdimer, which is in accordance with its difference in the NN distance.

Our study was extended to include the path connecting the cis- and trans- dimers. Table VI shows the optimized geometry for this TS at both CASSCF and CASPT2 levels. Focusing on the CASPT2 results, the predicted NN distance is longer than that of the cis- and trans- dimers, which indicates a weaker bond in the TS, the NO distance is slightly different from theirs, and the NNO angle is halfway that of the planar dimers. Most remarkable is the value of the ONNO dihedral angle, larger than $90^{\circ}$ as could be expected from Hammond's rule. The characterization of the cis- and trans-NO planar dimers along with the TS allows one to study the trans $\leftrightarrow$ cis isomerization and to relate it to the experimental information.

The energies for these three species indicate that the TS is situated only $0.29 \mathrm{kcal} / \mathrm{mol}$ above the less stable trans-NO dimer and as a consequence, below products $2 \mathrm{NO}$ in about $1.0 \mathrm{kcal} / \mathrm{mol}$. This value is much lower than the value estimated in a DFT study ${ }^{45}$ which reports an energy barrier of about $1.91 \mathrm{kcal} / \mathrm{mol}$. Moreover, if the $\triangle \mathrm{ZPE}$ and the BSSE 
are added to our calculation [for the TS an estimate of the BSSE was calculated at the CASPT2 $(14,12)$ level with respect to $\mathrm{NO}+\mathrm{NO}$ ], the TS locates $0.33 \mathrm{kcal} / \mathrm{mol}$ below the trans-NO dimer. Hence, the almost negligible energy barrier for the trans $\rightarrow$ cis conversion, and the smaller stability of the trans-with respect the cis-NO dimer, could explain the almost absence of available experimental information on the trans-NO dimer due to its rapid isomerization into the cis-NO dimer, even at low temperatures (24-32 K), in agreement with the experimental data. ${ }^{17,85}$ In fact, there is not an effective barrier in the path cis $\rightarrow$ trans $\rightarrow 2 \mathrm{NO}$ apart from its small BE.

With these data on cis-, trans-NO dimers and its isomerization TS, we have performed a study of the dimer dissociation constant $K_{c}$ [i.e., the inverse of reaction (1) for cis-NO dimer, trans-NO dimer, or cis +trans-NO dimers] and of the trans $\leftrightarrow$ cis isomerization, limited to the temperatures for which there exist some related experimental information. The equilibrium constants are calculated in terms of partition functions within the rigid rotor-harmonic oscillator approximation. Our results with the $\mathrm{BE}_{\mathrm{CP}}$ energies for the cis+trans dissociation at $100 \quad \mathrm{~K} \quad$ (i.e., 1.1 $\times 10^{22}$ molecule $\cdot \mathrm{cm}^{3}$ ) show a reasonable agreement with the only available old experimental value at the same temperature in gas-phase $\left((3 \pm 2) \times 10^{21}\right.$ molecule $\left.\cdot \mathrm{cm}^{3}\right) .{ }^{18}$ Our calculations show that $K_{c}$ increases with the temperature (e.g., $1.9 \times 10^{23}$ molecule $\cdot \mathrm{cm}^{3}$ at $\left.300 \mathrm{~K}\right)$. The values calculated at lower temperatures (e.g., $1.3 \times 10^{13}$ and 8.3 $\times 10^{15}$ molecule $\cdot \mathrm{cm}^{3}$ at 24 and $32 \mathrm{~K}$, respectively) are quite different from the experimental values obtained in a $\mathrm{N}_{2}$ matrix $^{17}\left(2.2 \times 10^{19}\right.$ molecule $\left.\cdot \mathrm{cm}^{3}, 24-32 \mathrm{~K}\right)$. However, as the same authors suggest, the different environment (i.e., gas-phase vs. Ar or $\mathrm{N}_{2}$ isolated matrices) should affect the binding energies and hence the equilibrium constant. The same effect has been observed in some of the measured vibrational frequencies (see Table III).

The calculated equilibrium constant for the trans $\leftrightarrow$ cis isomerization changes from $6.8 \times 10^{10}$ at $24 \mathrm{~K}$ to $8.3 \times 10^{15}$ at $32 \mathrm{~K}(0.21$ at $300 \mathrm{~K})$ and is also different with respect to the estimated value derived from $\mathrm{N}_{2}$ matrix experiments $\left(\mathrm{N}_{\text {cis }} / \mathrm{N}_{\text {trans }} \approx 4.85\right.$ at $\left.24-32 \mathrm{~K}\right),{ }^{17}$ possibly for the same reasons indicated above. We have checked numerically that closer values would be obtained if the cis- and trans-NO dimers had an almost equal binding energy.

\section{Symmetry problems in the study of the NO dimers}

We have encountered some symmetry-related problems when calculating the binding energy for the different electronic states of the NO dimers. For example, for the cis-NO dimer $\left(C_{2 v}\right)$ in its first singlet and triplet states $\left({ }^{1} A_{1}\right.$ and ${ }^{3} B_{2}$, respectively), when we calculate the absolute energies for the asymptote, $2 \mathrm{NO}$, in the supermolecule approach and $C_{2 v}$ symmetry for both the molecular frame and the wave function, we find an energy difference between these two states which varies with the method (CASSCF or CASPT2) and with the active space $[(14.12)$ or $(18,14)]$, amounting up to as much as $9 \mathrm{kcal} / \mathrm{mol}$. On the other hand, if we calculate both states in $C_{s}$ symmetry $\left({ }^{1} A^{\prime}\right.$ and ${ }^{3} A^{\prime \prime}$, respectively), thereby reducing only the wave function symmetry while keeping the $C_{2 v}$ molecular frame, their energies coincide. There are works in the literature ${ }^{40}$ dealing with several electronic states of different $\mathrm{NO}$ dimers in which this problem must also be present and does not seem to have been accounted for properly. The problem, as illustrated for the first singlet and triplet states of the dimers, is twofold: first, there is an energy difference in $C_{2 v}$ (and $C_{2 h}$ ) symmetry between the electronic states in the asymptote, and second, the spatial symmetry of the wave function for some of the states breaks on lowering the point group in which it is calculated.

As concerns the first problem, i.e., the origin of the energy difference between the various electronic states of the dimer, it can be better understood by first studying the situation in an isolated $\mathrm{NO}\left(X^{2} \Pi\right)$ molecule. For this molecule, in which one electron is placed in a degenerate $\pi^{*}$ system, there are two pictures of the electron distribution: one electron localized in only one of the two $\pi^{*}$ orbitals (i.e., $\pi_{2 p}^{*}$ or $\pi_{2 p^{\prime}}^{\prime *}$ "noncylindrical" description); or an even partition of the electrons in the $\pi^{*}$ system of the NO molecules ("cylindrical" description with "half an electron" in each $\pi^{*}$ orbital) thus keeping the correct $C_{\infty v}$ symmetry of the diatomic molecular frame. Thus, any approximate wave function for the NO should be of the cylindrical type. Whether it is or not of this type will condition, in particular, the geometry and binding energy of the dimers. For $2 \mathrm{NO}$ molecules at a certain intermolecular distance, the fourfold degeneracy of an $\mathrm{NO}\left(X^{2} \Pi\right)$ molecule (spin+space) leads to 16 distinct electronic states for $2 \mathrm{NO}\left(X^{2} \Pi\right)$ molecules, eight singlets and eight triplets, which can be grouped, neglecting the spinorbit and further effects, into eight states (electronic molecular terms), four singlets and four triplets. If we restrict ourselves to the $C_{2 v}$ and $C_{2 h}$ symmetries, the corresponding states are the following:

$$
\begin{aligned}
& C_{2 v}: 2{ }^{1} A_{1}, 2{ }^{3} B_{1},{ }^{1} B_{2},{ }^{3} B_{2},{ }^{1} A_{2},{ }^{3} A_{2}, \\
& C_{2 h}: 2{ }^{1} A_{g}, 2{ }^{3} B_{u},{ }^{1} A_{u},{ }^{3} A_{u},{ }^{1} B_{g},{ }^{3} B_{g} .
\end{aligned}
$$

We can divide these eight electronic states into two groups by the structure of their CASSCF wave function: those in which, among the four quasidegenerate $\pi^{*}$ derived MOs, there are only two orbitals involved in the two main CSFs of the CASSCF wave function (group I), composed in $C_{2 v}$ symmetry of the $2{ }^{1} A_{1}$ and $2{ }^{3} B_{1}$ states; and those in which there are always the four orbitals involved (group II), composed of the ${ }^{1} B_{2},{ }^{3} B_{2},{ }^{1} A_{2}$, and ${ }^{3} A_{2}$ states (see tables in next section). If one analyzes the situation in the asymptote, $2 \mathrm{NO}$, and considers a supermolecule CASSCF calculation, it can be seen that for group I there arises a noncylindrical description of the NO molecules, whereas for group II they are described in a cylindrical way. The energy difference between groups I and II in the asymptote (we will name it $\left.E_{\mathrm{I}}-E_{\mathrm{II}}\right)$ is, therefore, 2 times the energy difference in each one of the NO molecules looked at separately. An energy difference will also arise in the interacting region, thus reflecting the qualitative discrepancy between these two situations.

As concerns the symmetry breaking solutions, they exists in general (in both spin and space) in monodeterminantal SCF wave functions (the so-called "symmetry dilemma") $;{ }^{87}$ 
in this group there can be included the open-shell HF and DFT-KS (Kohn-Sham) wave functions. The breaking of spatial symmetry can also exist in multiconfigurational SCF wave functions (MCSCF) as have been recognized in literature $;{ }^{88-91}$ the important distinction between "real" (that is, the one motivated by, e.g., a Jahn-Teller distortion) and "artifactual" symmetry breaking (that is, the one due to limitations in the wave function, as is our case) has been noticed. Some methods have been applied ${ }^{91}$ to try and circumvent this problem, namely, doubling in size the active space ("orbital doubling") or performing a nonorthogonal CI (namely, a CASSI approach). This latter approach was applied by Roos et al. to the $\mathrm{Ni}_{2}^{+}\left({ }^{4} \Sigma_{u}^{-}\right)$molecule, ${ }^{91}$ but the results were not considered fully satisfactory by the authors because of an overestimation of the binding energy. The main conclusion of that study was that although there is a large energy difference between the higher $\left(D_{2 h}\right)$ and lower $\left(C_{2 v}\right)$ symmetry curves, this difference remains almost constant with respect to the internuclear distance, and that it is actually possible to perform the calculation in the higher symmetry and still obtain a reasonable potential curve (in fact, their $D_{2 h}$ results are in better agreement with the experimental values than their $C_{2 v}$-CASSI ones).

We can now apply these considerations to our problem, in which for the states of group II as defined above, the CASSCF calculations give an energy lower (and equal to that in group I) for the symmetry broken $\left(C_{2 v}\right.$ in $\mathrm{Ni}_{2}^{+}$case, $C_{s}$ in ours) than for the symmetry-keeping solution $\left(D_{2 h}\right.$, and $C_{2 v}$ or $C_{2 h}$, respectively), whereas the subsequent CASPT2 calculations reverse the energy order (as in Fig. 1 in Ref. 91). In analogy with that work, we have checked on whether the CASPT2 $C_{2 v}$ and $C_{s}$ curves are approximately parallel in the case of the lowest triplet states $\left({ }^{3} B_{2}\right.$ or ${ }^{3} A^{\prime \prime}$, respectively) of the cis-NO dimer varying only the NN distance, and found that it is approximately so: the $C_{s} \mathrm{NN}$ distance and binding energy are about $3.18 \AA$ and $0.82 \mathrm{kcal} / \mathrm{mol}$ (as compared to $2.99 \AA$ and $1.08 \mathrm{kcal} / \mathrm{mol}$, respectively, for the $C_{2 v}$ case). If we assume that the same holds true for the other three states in group II, we can accept the symmetrykeeping solution as the correct one for each of them; it seems also reasonable to compare the $C_{2 v} / C_{2 h}$ curves for these states with those in group I, i.e., we can consider that both groups of states have a common asymptote and "rescale" the whole curves by the amount $E_{\mathrm{I}}-E_{\mathrm{II}}$ at each level of calculation considered. Thus, this argument, derived from the analysis of symmetry breaking, provides a way of overcoming the energy difference problem. It is under these assumptions that we present the results in the next section.

There is a certain relationship between the two problems analyzed above. The differences between the cylindrical and noncylindrical descriptions are present because the CASSCF function is limited (in a full CI calculation, their energy must coincide), ${ }^{89}$ whereas it is known that for MCSCF wave functions more than one solution can exist in general because of the nonlinearity of the self-consistent method. The symmetry breaking problem arises in situations when two or more configurations cannot be treated with comparable accuracy, thus leading to instabilities in the wave function; these instabilities may, but not necessarily do, break the symmetry of the

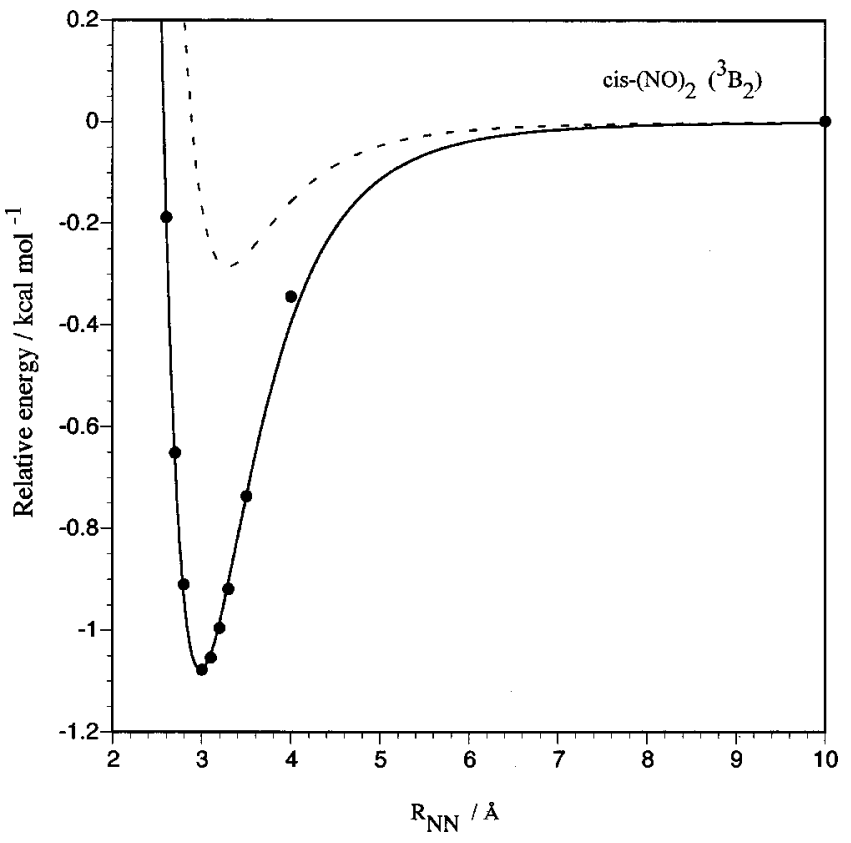

FIG. 3. Ab initio CASSCF/CASPT2(18/14)/6-311G(2d) curve of the energy of the cis-NO dimer in its lowest triplet state as a function of the $\mathrm{NN}$ distance. The NO distances and the NNO angles are kept fixed at the optimal values of the singlet state: $R_{\mathrm{NO}}=1.1594 \AA$ and $\angle \mathrm{NNO}=94.5^{\circ}$. Curves represent an analytical fit by means of an exp-6 curve [Eq. (15)] solid line (without BSSE) and dashed line (with BSSE).

wave function. ${ }^{88-96}$ Quite surprisingly, even for the very large active spaces used in this work, $(14,12)$ and $(18,14)$, both problems are present. There seem to be several ways of dealing equivalently with all the considered electronic states: a CASSI+CASPT2 approach would accept the symmetry broken solution for the states in group II and try to symmetrize and bring them to a description equivalent to those in group I, whereas an average between the states in group I (i.e., in $C_{2 v}$ they would be $2{ }^{1} A_{1}$ on the one hand and $2{ }^{3} B_{1}$ on the other) would try to make them similar to those in group II. A third possibility, in principle, would be to perform all the calculations in $C_{s}$ symmetry, given the coincidence of the energy of the eight electronic states in the $2 \mathrm{NO}$ asymptote and the fact that the $C_{2 v} / C_{2 h}$ curves are almost parallel to the $C_{s}$ ones. In this case, group I are nonsymmetry breaking and group II, symmetry breaking states. This approach is not feasible, because it is known that the symmetry problem in the wave function reflects itself in the geometric structure..$^{90}$ Therefore, all these approaches are probably very costly for the extensive study presented here, or they do not even work (we have checked it for the state averaging and for the $C_{s}$ reduction of symmetry). We believe that the best compromise solution is to accept the $C_{2 v} / C_{2 h}$ solutions as the correct ones, as we have carried out.

\section{Calculated properties of the first triplet state for the cis- and trans-NO dimers}

We have performed a CASSCF/CASPT2 study of the lowest triplet state of the cis-and trans-NO dimers, under the assumptions commented on in the last section. Figures 3 and 4 depict analytical fits [using Eq. (15)] of the 


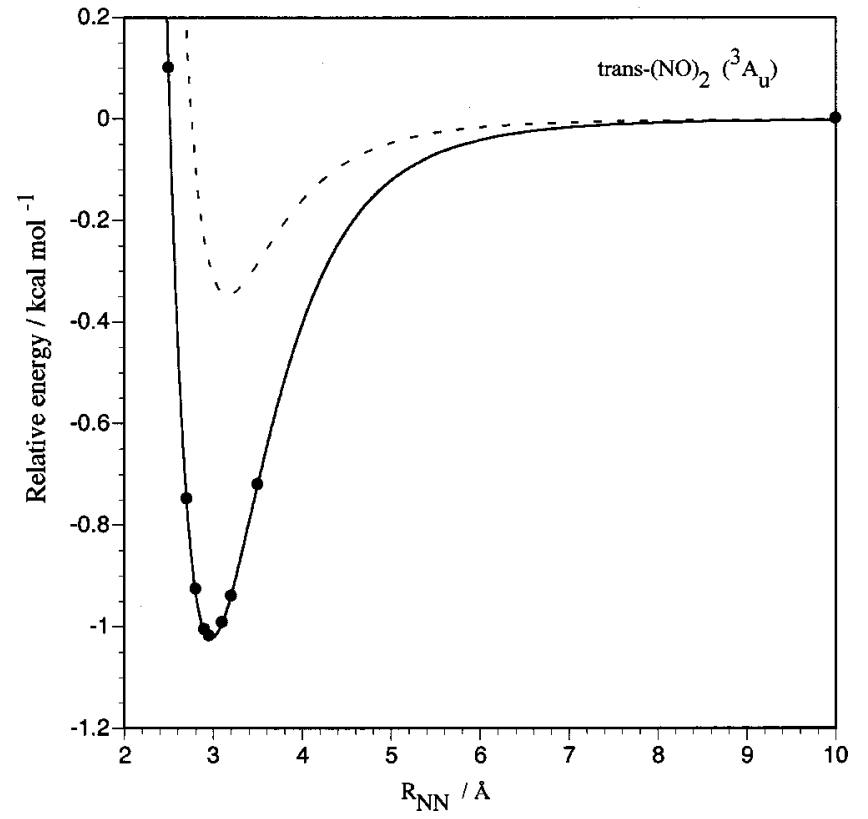

FIG. 4. Ab initio CASSCF/CASPT2(18/14)/6-311G(2d) curve of the energy of the trans-NO dimer in its lowest triplet state as a function of the NN distance. The NO distances and the NNO angles are kept fixed at the optimal values of the singlet state: $R_{\mathrm{NO}}=1.1594 \AA$ and $\angle \mathrm{NNO}=109.1^{\circ}$. Curves represent an analytical fit by means of an exp-6 curve [Eq. (15)]: solid line (without BSSE) and dashed line (with BSSE).

CASSCF/CASPT2(18,14)/6-311G(2d) energies, with and without the BSSE, corresponding to the lowest triplet states $\left({ }^{3} B_{2}\right.$ and $\left.{ }^{3} A_{u}\right)$ of both dimers as a function of the NN distance. The NO distances and the NNO angles were kept fixed at the values of their lowest singlet states. Table VII summarizes the parameters of these exp- 6 fits and the $\mathrm{BE}, \mathrm{BE}_{\mathrm{CP}}$, and the optimum NN distance for these dimers. The lengthening of the NN distance is remarkable with respect to the analogous singlet curves, and the decrease in their stabilities, their magnitudes being very little once added the BSSE. As for the singlet curves, the addition of the BSSE leads to a longer NN distance. The trans singlet and triplet curves are more similar than their cis counterparts. Singlet states are always the lowest ones for both dimers, and the cis-dimers are more stable than the trans-dimers in the lowest singlet and triplet states. Nevertheless, it must be taken into account that the results for the little stable triplet dimers could have changed slightly if a complete geometrical optimization would have been performed.

The lower stability and longer NN distance of the triplet cis-NO dimer $\left({ }^{3} B_{2}\right)$ with respect to the singlet $\left({ }^{1} A_{1}\right)$ could be explained by the fact that the triplet state wave function differs mainly from the singlet one by two single excitations, namely, following the notation in Table $\mathrm{V}$, 4th $a_{1} \rightarrow 2$ nd $b_{2}$ ( $\sigma$ and $\pi$ bonding, respectively, with respect to the NN bond) and 4 th $b_{1} \rightarrow 2$ nd $a_{2}$ ( $\sigma$ and $\pi$ antibonding), thus implying a weakening of the NN bond (the $\pi$ bonding is expected to be weaker than the $\sigma$ one) and a decrease in stability of the triplet state in its equilibrium geometry. On the other hand, the lower stability of the trans-NO dimer $\left({ }^{1} A_{g}\right)$ with respect to the cis-one $\left({ }^{1} A_{1}\right)$ could be attributed to the larger ratio between the coefficients of the antibonding and bonding con- figurations in the former (i.e., and referring again to Table $\mathrm{V}$, $0.57 / 0.74 \approx 0.77$ for the trans-and $0.44 / 0.82 \approx 0.54$ for the cis-dimer).

A comparison with existing ab initio studies of the singlet and triplet cis- and trans-NO dimers ${ }^{35,46}$ reveals some differences with the present work. In Benzel et al. ${ }^{35} \mathrm{SCF} / \mathrm{DZ}$ geometric optimization of the singlet cis- and trans-NO dimers are carried out, yielding the singlet trans-NO dimer form as the most stable and the triplet states always higher in energy than the singlet ones; however, MP2 pointwise calculations on the singlet states reverse the order, thus placing the singlet cis- lower than the singlet trans-NO dimer in accord with the present results.

Recently, Salahub et al. ${ }^{41,46}$ have performed a more extensive study with a variety of DFT functionals, in which full geometric optimization was made, obtaining in this case the triplet cis-NO dimer as the most stable species. Although reasonable geometries were found (however, NN distances were shorter by about $0.1 \AA$ for the cis-NO dimer), binding energies were overestimated in comparison with the experimental values (see Tables III and IV). Thus, their calculated $\mathrm{BE}_{\mathrm{CP}}$ for the fully optimized geometries range in the intervals 6.12 to 11.86 and 6.77 to $14.62 \mathrm{kcal} / \mathrm{mol}$ for the cis-NO dimer in its singlet and triplet states, respectively; for the trans-NO dimer the following intervals were observed: 3.20 to 7.19 and 6.59 to $13.98 \mathrm{kcal} / \mathrm{mol}$, respectively. The authors suggest as a possible explanation of this large overestimation of the BE by all DFT methods the high degree of multireference character of these states (in the present work it is observed that at least two CSFs are necessary for each state, Table V) that could be a rather serious obstacle for an adequate DFT treatment. In that work it is found that the first singlet state of each dimer was higher in energy than the triplet one at their optimum geometries (i.e., from 0.30 to $3.61 \mathrm{kcal} / \mathrm{mol}$ and from 3.29 to $7.06 \mathrm{kcal} / \mathrm{mol}$, respectively) in opposite behavior to the results of our work and to the usual assumption that the ground states of the cis- and trans-NO dimers should be singlets.

A careful analysis of BE computed at DFT level shows that there is a remarkable parallelism between the CASSCF/ CASPT2 and DFT approaches concerning the dependence of the results on the symmetry of the wave function. We have studied this parallelism briefly by repeating and extending some of the DFT calculations performed by Salahub et al. ${ }^{46}$ We have used the GAUSSIAN 94 package $^{97}$ restricting ourselves to the BP86 functional (i.e., Becke 88 expression for exchange and Perdew 86 expression for correlation), and with the standard 6-311+G(d) basis set, which we think is the closest to their set available to us. The results we obtain (Table VIII) are similar enough for our purposes to those by Salahub et al. Most important are the results obtained at the 2 NO asymptote: 2 times the energy of an NO monomer $(2 \times \mathrm{NO})$ is not necessarily equal to the 2 NO energy computed as a supermolecule. To be precise, and as Table VIII indicates, the supermolecule broken symmetry energy (i.e., understood in the sense of an unrestricted wave function) does equal that of $2 \mathrm{NO}$ monomers, but if we prolong the ${ }^{3} B_{2}$ curve (lowest triplet at the cis optimum geometry) to the asymptotic limit, we find an energy difference with the 
TABLE VIII. Properties of the optimized singlet and triplet cis-NO dimers at the BP86/6-311G+(d) level of theory.

\begin{tabular}{lccccccccccccc}
\hline \hline State & Energy (H) & $\begin{array}{c}R_{\mathrm{NN}} \\
(\AA)\end{array}$ & $\begin{array}{c}R_{\mathrm{NO}} \\
(\AA)\end{array}$ & $\begin{array}{c}\mathrm{N}_{\mathrm{N}} \mathrm{O} \\
(\mathrm{o})\end{array}$ & $\begin{array}{c}\mu_{e} \\
(\mathrm{D})\end{array}$ & $\begin{array}{c}\mathrm{BE}^{\mathrm{a}} \\
(\mathrm{kcal} / \mathrm{mol})\end{array}$ & $\begin{array}{c}\Delta \mathrm{ZPE}^{\mathrm{b}} \\
(\mathrm{kcal} / \mathrm{mol})\end{array}$ & $a_{1}$ & $a_{1}$ & $a_{1}$ & $b_{1}$ & $b_{1}$ & $a_{2}$ \\
\hline${ }^{1} A_{1}$ & -259.891061 & 2.0626 & 1.1624 & 99.9 & 0.1072 & 9.91 & 1.92 & 261.9 & 384.4 & 1865.5 & 656.7 & 1715.7 & 228.6 \\
${ }^{3} B_{2}$ & -259.899026 & 2.0371 & 1.1641 & 111.4 & 0.1529 & $14.91(17.80)$ & 1.41 & 159.5 & 338.3 & 1847.9 & 473.3 & 1684.8 & 253.2 \\
\hline \hline
\end{tabular}

${ }^{\text {a} B i n d i n g ~ e n e r g y ~ w i t h ~ r e s p e c t ~ t o ~ t w o ~ n o n c y l i n d r i c a l ~ N O ~ m o l e c u l e s ~}\left(2 \times E_{\mathrm{NO}}=-259.875253 \mathrm{H}\right.$ at the optimum distance of $\left.1.1615 \AA\right)$ calculated separately at the same level of theory. In parentheses the BE calculated using the asymptote NO+NO at $20 \AA$ for the ${ }^{3} B_{2}$ curve $(-259.870658 \mathrm{H})$.

${ }^{\mathrm{b}}$ Difference of calculated zero-point vibrational energy between the $c i s-\mathrm{NO}$ dimer and the NO+NO asymptotic energy. $\mathrm{BE}-\Delta \mathrm{ZPE}=D_{0}$ is the binding energy of the van der Waals dimer with zero-point vibrational energy corrections.

${ }^{c}$ Harmonic vibrational frequencies which correspond to: sym. NNO bend, NN str., sym. NO str., asym. NNO bend, asym. NO str. and torsion modes, respectively. The molecule is lying in the $\mathrm{XZ}$ plane, with the $z$-axis as the $C_{2}$ axis for the $\left({ }^{14} \mathrm{~N}^{16} O\right)_{2}$ dimer.

former of about $3 \mathrm{kcal} / \mathrm{mol}$. Moreover, if we lower the symmetry of the triplet wave function to $C_{s}$, we recover the coincidence with the broken symmetry and $2 \times \mathrm{NO}$ energies. If we correct for the energy difference in the asymptote following our criterion about comparing different states, we find a cis-NO dimer triplet stability even larger (i.e., 17.80 $\mathrm{kcal} / \mathrm{mol}$ ) than that calculated by taking the $2 \times \mathrm{NO}$ asymptote. Therefore, the results are in greater contradiction with the experimental evidence and with our ab initio study. We think that similar deviations, either for or against the experiment, could be found in other DFT previous calculations where this correction was not considered.

\section{E. Vertical energies of the cis- and trans-NO dimers}

Further single point calculations have been carried out of the vertical energies corresponding to the eight lowest electronic states of cis- and trans-NO dimers calculated at the optimal geometries of their corresponding lowest singlet and triplet states (see Tables II, VI, and VII) at the CASPT2 $(18,14) / 6-311 G(2 d)$ level. Figure 5 shows a sketch of the energetic ordering in each geometry. The energies calculated with the $(14,12)$ and $(18,14)$ active spaces are very alike. For the cis singlet state, it is remarkable the relatively large separation of states (about $20 \mathrm{kcal} / \mathrm{mol}$, Table IX), the ${ }^{3} B_{2}$ being the first excited state $\left(7.3 \mathrm{kcal} / \mathrm{mol}\right.$ above $\left.{ }^{1} A_{1}\right)$; only the first ${ }^{1} A_{1}$ state is below products, $2 \mathrm{NO}$, at this geometry. The ordering and the relative spacings of these eight low-lying states (i.e., ${ }^{1} A_{1},{ }^{3} B_{2},{ }^{1} B_{2}, 2$ nd ${ }^{1} A_{1},{ }^{1} A_{2},{ }^{3} A_{2}$, ${ }^{3} B_{1}, 2$ nd $\left.{ }^{3} B_{1}\right)$ is in close agreement with that obtained by East $^{40}$ (in this article the $Y Z$ plane was the molecular plane instead of the $X Z$ plane used in the present work. Thus, $B_{2}$ and $B_{1}$ states will be interchanged) at a MRCI/cc-pVTZ level based in $\operatorname{CASSCF}(2,6)$ calculations at the experimental geometry of the cis-NO dimer (i.e., ${ }^{1} A_{1},{ }^{3} B_{2}$, ${ }^{1} B_{2}, 2$ nd ${ }^{1} A_{1},{ }^{3} B_{1},{ }^{3} A_{2},{ }^{1} A_{2}, 2$ nd $\left.{ }^{3} B_{1}\right)$. For instance, in that work the ${ }^{3} B_{2}$ excitation energy was equal to 6.3 $\pm 2.9 \mathrm{kcal} / \mathrm{mol}$ above the ground ${ }^{1} A_{1}$ state. On the other hand, the computed difference between the 5 th and the 7 th electronic states is very small [e.g., $0.69-0.84 \mathrm{kcal} / \mathrm{mol}$ at the CASPT2 $(18,14)$ level to be compared with $0.70 \mathrm{kcal} / \mathrm{mol}$

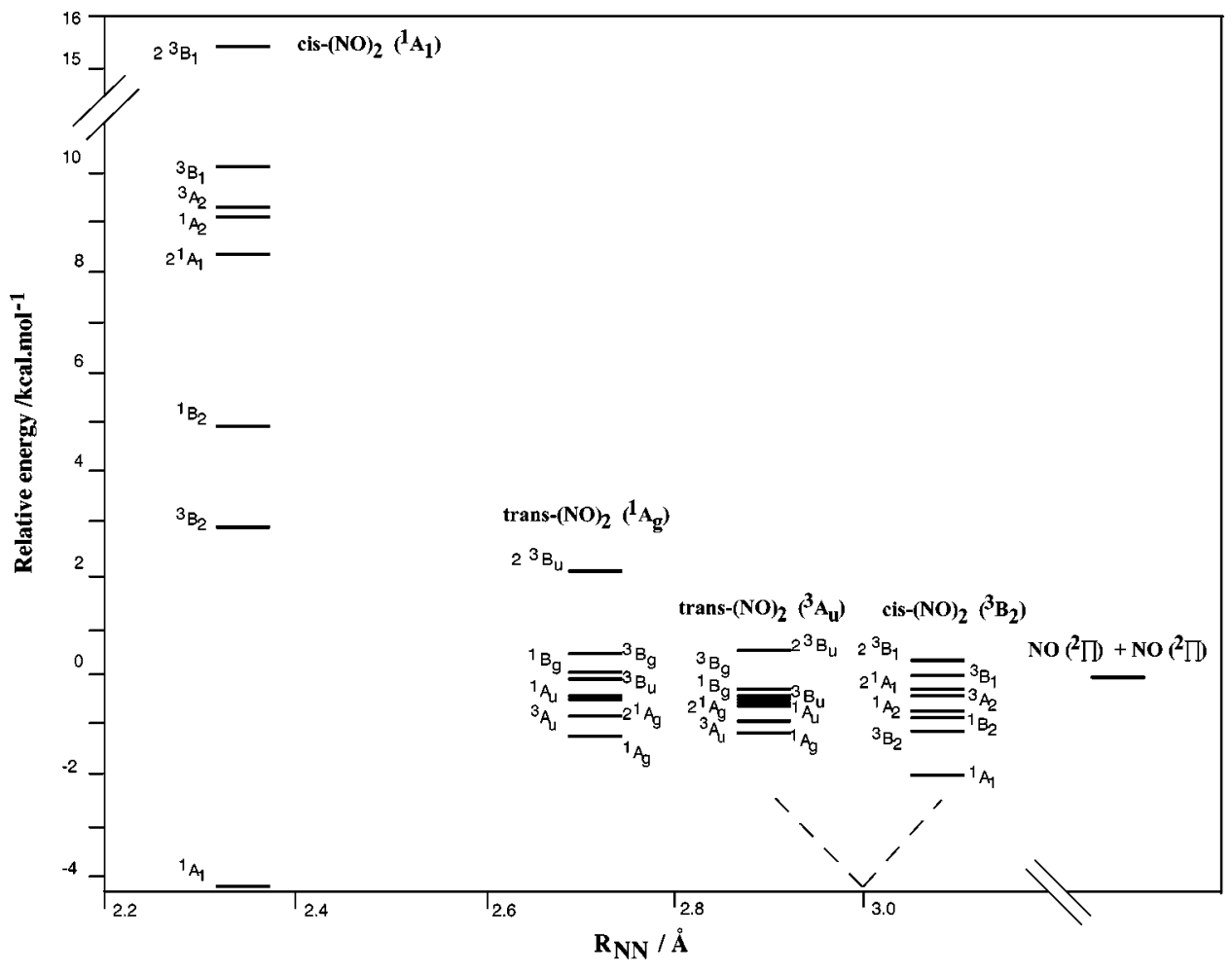

FIG. 5. Computed CASSCF/ CASPT2(18/14)/6-311G(2d) energies of the eight lowest electronic states of the cis-and trans-NO dimers at the optimal geometries of their corresponding lowest singlet and triplet states. The zero of energy is taken in $\mathrm{NO}\left({ }^{2} \Pi\right)+\mathrm{NO}\left({ }^{2} \Pi\right)$ to facilitate their comparison in the same diagram. 
TABLE IX. Calculated vertical excitation energies at the CASSCF/ CASPT2(18/14) level for the cis-NO dimer at the optimum geometry of the ground ${ }^{1} A_{1}$ state (see Table II). ${ }^{\mathrm{a}}$

\begin{tabular}{lccl}
\hline \hline $\begin{array}{c}\text { Electronic } \\
\text { states }\end{array}$ & $\begin{array}{c}E_{\text {CASSCF }} \\
(\mathrm{kcal} / \mathrm{mol})\end{array}$ & $\begin{array}{c}E_{\text {CASPT2 }} \\
(\mathrm{kcal} / \mathrm{mol})\end{array}$ & \multicolumn{1}{c}{ CI vector $^{\mathrm{b}}$} \\
\hline${ }^{1} A_{1}$ & $0.00(0.00)$ & $0.00(0.00)$ & $0.82(2000)-0.44(0020)$ \\
${ }^{3} B_{2}$ & $5.56(5.46)$ & $7.25(7.29)$ & $0.79(1001)+0.50(0110)$ \\
${ }^{1} B_{2}$ & $7.24(7.15)$ & $9.16(9.16)$ & $0.78(1001)+0.52(0110)$ \\
2 nd $^{1} A_{1}$ & $10.71(10.71)$ & $12.55(12.60)$ & $0.60(0200)-0.71(0002)$ \\
${ }^{1} A_{2}$ & $11.16(11.26)$ & $13.47(13.95)$ & $0.73(1100)+0.57(0011)$ \\
${ }^{3} A_{2}$ & $11.28(11.37)$ & $13.56(14.05)$ & $0.74(1100)+0.56(0011)$ \\
${ }^{3} B_{1}$ & $11.96(12.10)$ & $14.31(14.64)$ & $0.94(0101)$ \\
2 2nd ${ }^{3} B_{1}$ & $17.19(17.37)$ & $19.75(20.21)$ & $0.94(1010)$ \\
\hline \hline
\end{tabular}

${ }^{a}$ Energies referred to the lowest ${ }^{1} A_{1}$ state. The geometry was optimized with the $6-311 \mathrm{G}(2 d)$ basis set. Energies in parentheses are values for 6-311 $+\mathrm{G}(2 d)$ basis set (see text).

${ }^{b}$ Coefficients of the two principal CSFs in the CASSCF wave function [6-311G $(2 d)$ basis set]. The parentheses show the two-electron occupation of the four orbitals (4th $a_{1}, 2$ nd $a_{2}, 4$ th $b_{1}, 2$ nd $b_{2}$ ) deriving from the $\pi^{*}$ orbitals of the separate NO monomers (i.e., in each NO molecule one electron occupies a $\pi^{*}$ orbital). These 4 MOs vary their occupation in the two main CSFs of the different electronic states (see Table V for the rest of the MO of the $\left.1{ }^{1} A_{1}\right)$.

at the MRCI level], and the relative ordering of the three states comprised could also change depending on the accuracy of the $a b$ initio method. The same author observes that the relative energy between the 5th and the 6th electronic states (i.e., ${ }^{3} B_{1}<{ }^{3} A_{2}$ ) decreases significantly from $\operatorname{CCSD}(\mathrm{T})$ to the most accurate MRCI calculations (see Fig. 7 in Ref. 40). On the other hand, the problem mentioned in the previous section on the CASSCF $(2,6) / \mathrm{cc}-\mathrm{pVTZ}$ energies for the $\mathrm{NO}+\mathrm{NO}$ asymptotes, should be possibly somewhat lower for the MRCI asymptotes, although its introduction could modify slightly some of his excitation energies.

The predicted ordering of states at the trans singlet geometry is similar to the cis one but the energy gap between the states has been considerably reduced (i.e., it is about 3.4

TABLE X. Calculated vertical excitation energies at the CASSCF/ CASPT2(18/14) level for the trans-NO dimer at the optimum geometry of the ground ${ }^{1} A_{g}$ state (see Table VI). ${ }^{\mathrm{a}}$

\begin{tabular}{lccl}
\hline \hline $\begin{array}{c}\text { Electronic } \\
\text { states }\end{array}$ & $\begin{array}{c}E_{\text {CASSCF }} \\
(\mathrm{kcal} / \mathrm{mol})\end{array}$ & $\begin{array}{c}E_{\mathrm{CASPT} 2} \\
(\mathrm{kcal} / \mathrm{mol})\end{array}$ & \multicolumn{1}{c}{ CI vector ${ }^{\mathrm{b}}$} \\
\hline${ }^{1} A_{g}$ & $0.00(0.00)$ & $0.00(0.00)$ & $0.74(2000)-0.57(0020)$ \\
${ }^{3} A_{u}$ & $-0.085(-0.14)$ & $0.40(0.45)$ & $0.71(1100)-0.60(0011)$ \\
2 nd $^{1} A_{g}$ & $0.32(0.29)$ & $0.77(0.76)$ & $0.68(0200)-0.64(0002)$ \\
${ }^{1} A_{u}$ & $0.41(0.35)$ & $0.86(0.85)$ & $0.70(1100)+0.60(0011)$ \\
${ }^{3} B_{u}$ & $0.51(0.47)$ & $1.16(1.17)$ & $0.94(0101)$ \\
${ }^{1} B_{g}$ & $0.83(0.78)$ & $1.30(1.28)$ & $0.69(1001)+0.63(0110)$ \\
${ }^{3} B_{g}$ & $1.01(0.96)$ & $1.67(1.71)$ & $0.74(1001)-0.56(0110)$ \\
2 nd $^{3} B_{u}$ & $2.77(2.73)$ & $3.40(3.42)$ & $0.94(1010)$ \\
\hline
\end{tabular}

anergies referred to the lowest ${ }^{1} A_{g}$ state. The geometry was optimized with the $6-311 \mathrm{G}(2 d)$ basis set. Energies in parentheses are values for 6-311 $+\mathrm{G}(2 d)$ basis set (see text).

${ }^{\mathrm{b}}$ Coefficients of the two principal CSFs in the CASSCF wave function [6-311G $(2 d)$ basis set]. The parentheses show the two electron occupation of the four orbitals (4th $a_{g}, 2$ nd $a_{u}, 4$ th $b_{u}, 2$ nd $b_{g}$ ) deriving from the $\pi^{*}$ orbitals of the separate NO monomers (i.e., in each NO molecule one electron occupies a $\pi^{*}$ orbital). These four MOs vary their occupation in the two main CSFs of the different electronic states (see Table V for the rest of the MO of the ${ }^{1} A_{g}$ ). $\mathrm{kcal} / \mathrm{mol}$, Table X). In the cis- and trans-triplet optimum geometries the states are very much close together, and only both ${ }^{3} B_{1}$ states and the ${ }^{3} B_{u}$ state are a little above products (i.e., $0.4-0.6 \mathrm{kcal} / \mathrm{mol}$ ), the rest of states being stable. Figure 5 shows that the longer the $\mathrm{NN}$ distance in the $\mathrm{NO}$ dimer, the closer to each other and with respect to $2 \mathrm{NO}$ the electronic states are, as should be expected (i.e., the eight degenerate electronic states derive from $2 \mathrm{NO}\left(X^{2} \Pi\right)$ molecules $)$.

Finally, we note that the addition of diffuse functions is of minor importance in the calculation of the vertical energies (i.e., Tables IX and X). This conclusion is in agreement with a recent $a b$ initio study, ${ }^{40}$ and it is due to the nonRydberg character of the eight NO-dimer states considered in this case (i.e., valence states), which arise from the $X^{2} \Pi$ states of the two NO molecules. Only in those dimer states in which participate the Rydberg $A^{2} \Sigma$ of NO or ionic states of $\mathrm{NO}$ (i.e., those correlating with $\mathrm{NO}^{+}+\mathrm{NO}^{-}$) ${ }^{40}$ is it expected that diffuse functions play a relevant role. We also recall that at the CASSCF level the $6-311 \mathrm{G}+(2 d)$ basis set worsens the geometries of the cis- and trans-NO dimers; the same tendency was observed in several DFT calculations of the cis-NO dimer. ${ }^{43}$ Nevertheless, it is reasonable to assume that the incorporation of diffuse functions on the geometric optimization at the CASPT2 level, would not alter to a great extent the results obtained with the $6-311 \mathrm{G}(2 d)$ basis set. The inclusion of the dynamical correlation is the most important factor in the determination of the $\mathrm{NN}$ distance and compensates clearly the opposite basis set effect.

In further calculations we performed, the six states which are the lower in their symmetry were optimized for $c i s$ and trans geometries at the $\operatorname{CASSCF}(18,14) / 6-311 \mathrm{G}(2 d)$ level, all of them resulting stable with respect to $2 \mathrm{NO}$, even though their NN distance was very long (from 3.40 to $4.1 \AA$ ) and their BE quite small (from 0.01 to $0.30 \mathrm{kcal} / \mathrm{mol}$ ). Pointwise CASPT2 calculations increased their stability (from 0.05 to $0.80 \mathrm{kcal} / \mathrm{mol}$ ) and would possibly shorten the NN distance and increase the stability had a geometric optimization been carried out.

In all the calculations we have neglected the spin-orbit effect. The $X^{2} \Pi$ state of the NO molecule splits into ${ }^{2} \Pi_{1 / 2}$ and ${ }^{2} \Pi_{3 / 2}(\Delta=0.34 \mathrm{kcal} / \mathrm{mol}){ }^{74}$ This small interaction, in turn, splits the $2 \mathrm{NO}$ asymptote into three: ${ }^{2} \Pi_{1 / 2}+{ }^{2} \Pi_{1 / 2}$ $(-\Delta)^{2} \Pi_{1 / 2}+{ }^{2} \Pi_{3 / 2}$ [this asymptote coincides with the unsplit $\left.\quad \mathrm{NO}\left({ }^{2} \Pi\right)+\mathrm{NO}\left({ }^{2} \Pi\right)\right], \quad$ and $\quad{ }^{2} \Pi_{3 / 2}+{ }^{2} \Pi_{3 / 2}(+\Delta)$. Experimentally, ${ }^{9,10}$ the $\nu_{3}+\nu_{5}$ IR excitation of the cis-NO dimer produces mainly $(77 \% \pm 7 \%)$ the ${ }^{2} \Pi_{1 / 2}+{ }^{2} \Pi_{3 / 2}$ channel and the rest $(21 \pm 5 \%)$ via the ${ }^{2} \Pi_{1 / 2}+{ }^{2} \Pi_{1 / 2}$ channel. The $2 \nu_{5}$ IR excitation increases $(39 \pm 6 \%)$ the extent of the ${ }^{2} \Pi_{1 / 2}+{ }^{2} \Pi_{1 / 2}$ channel. Thus, the derived experimental averaged $D_{0}$ energies [with values of the uncertainties similar to $\Delta$ (Table III)] could be directly compared with the ab initio values referred to the $\mathrm{NO}\left({ }^{2} \Pi\right)+\mathrm{NO}\left({ }^{2} \Pi\right)$, and this spinorbit effect would not affect our main conclusion regarding the relative stability of the singlet and triplet cis- and trans-NO dimers; moreover, the spin-orbit effect would also extend to the $(\mathrm{NO})_{2}$ interacting region, making the possible correction in $\mathrm{BE}$ even smaller. 


\section{CONCLUSIONS AND REMARKS}

We have performed a systematic study on the planar cis-and trans-NO dimers at the CASSCF and CASPT2 levels of calculation, focusing on the lowest eight electronic (singlet and triplet) states. The geometry, frequencies, dipole moment, binding energy, and vertical excitation energies are predicted with an accuracy close or even better than the best reported $a b$ initio results for some of these properties [e.g., MRCI, ACPF, or CCSD(T) methods] and in very good agreement with the available experimental data.

A comparison between the CASSCF and CASPT2 or MRCI calculations makes evident the need of accounting for the dynamical correlation in some way to describe these shallow dimers. Concerning the active space used, we preferred the $(18,14)$ because it is marginally superior to the $(14,12)$ and for the sake of consistency with parallel work we are performing on the $\mathrm{O}\left({ }^{1} D\right)+\mathrm{N}_{2} \mathrm{O}$ reaction. One can expect a convergence of the calculated CASPT2 $(18,14)$ properties of the cis-NO dimer (e.g., $\mathrm{BE}_{\mathrm{CP}}$ or dipole moment) with respect to the increase in size and quality of the basis set, although a geometrical optimization of both the dimer and the NO monomer could be necessary in order to improve further the results obtained. The inclusion of the dynamical correlation by means of the MRCI method yields values of BE not very different from those obtained at the CASPT2 level. The good values obtained in any case with the 6-311G $(2 d)$ basis set, if only approximate for the dipole moment, combined with its moderate size, justify its election as the basis set used throughout this extensive study. Moreover, not only are BSSE corrections necessary in order to determine accurately the binding energies, but they are also important for predicting the geometry (especially the NN distance) of these dimers.

A problem with the symmetry of the wave function has been noticed for the NO dimers and for the $\mathrm{NO}+\mathrm{NO}$ asymptote. In analogy with previous studies, this problem can be circumvented if one takes into account the weak bonding in any of the electronic states, which allows one to take the symmetry-keeping solutions as approximately correct and comparing them after a proper rescaling of the energies.

Present results show the existence of at least four shallow NO-dimers (i.e., two cis-(NO) ${ }_{2}\left({ }^{1} A_{1}\right.$ and $\left.{ }^{3} B_{2}\right)$ and two trans-(NO) ${ }_{2}\left({ }^{1} A_{g}\right.$ and $\left.\left.{ }^{3} A_{u}\right)\right)$, although CASSCF optimization on the lowest excited electronic states indicates that less stable dimers could also be found once the dynamical correlation is added. The vertical excitation energies were calculated for these four dimers. For the cis-NO dimer, the ordering and the spacings of the excited states (i.e., ${ }^{1} A_{1},{ }^{3} B_{2},{ }^{1} B_{2}, 2$ nd ${ }^{1} A_{1},{ }^{1} A_{2},{ }^{3} A_{2},{ }^{3} B_{1}, 2$ nd $\left.{ }^{3} B_{1}\right)$ are very close to those found in MRCI previous studies. The singlet cis-NO dimer $\left({ }^{1} A_{1}\right)$ is the most stable in almost quantitative accord with the experimental data. The addition of diffuse basis functions has been found not to be very important for the main part of the present study, with the exception of the dipole moment calculations. On the other hand, none of the DFT studies has to our knowledge, given good estimates of all these properties in a balanced way (e.g., whenever the geometries are rather good the $\mathrm{BE}$ are quite different from the experimental ones) and some of them predict erroneously that triplet cis- or trans-NO dimers are more stable than singlet ones. In fact, DFT studies predict a similar NN distance for both dimers, whereas present and previous ab initio studies show a much longer NN distance for the trans-NO dimer and as a consequence, a smaller stability.

A nonplanar transition state for the singlet trans $\leftrightarrow$ cis isomerization has also been characterized, and shows a negligible energy barrier, which indicates a rapid isomerization to the most stable cis-NO dimer at low temperatures. This behavior would be in agreement with the experimental difficulties to detect the trans-NO dimer.

Very recent experimental studies on the dynamics of the reaction Eq. (14) attach quite an unexpected importance to the NO dimers. Therefore, a potential surface for this reaction describing these and other high-energy $\mathrm{N}_{2} \mathrm{O}_{2}$ isomers with a similar and good accuracy seems mandatory if one has to perform theoretical dynamic studies on this reaction. This study is in progress in our laboratory.

\section{ACKNOWLEDGMENTS}

This work has been supported by the "Dirección General de Enseñanza Superior (Programa Sectorial de Promoción General del Conocimiento)" of the Spanish Ministry of Education and Culture (DGES Project Ref. PB95-0598-C0201). Financial support from the "Generalitat" (Regional Government) of Catalonia Ref. 1998SGR 0008 is also acknowledged. R.V. also thanks the "Generalitat" for a "beca de formació d'investigadors" research grant. The authors are also grateful to the "Centre de Computació i Comunicacions de Catalunya (C4)" for providing a part of the computer time.

${ }^{1}$ M. Rigby, E. B. Smith, W. A. Wakeham, and G. C. Maitland, The Forces Between Molecules (Oxford Science, Oxford, 1986), Chap. 3.

${ }^{2}$ G. Chalasinski and M. N. Szczesniak, Chem. Rev. 94, 1723 (1994).

${ }^{3}$ B. J. Howard and A. R. W. Mckellar, Mol. Phys. 78, 55 (1993).

${ }^{4}$ A. R. W. McKellar, J. K. G. Watson, and B. J. Howard, Mol. Phys. 86, 273 (1995).

${ }^{5}$ A. Dkhissi, P. Soulard, A. Perrin, and N. Lacome, J. Mol. Spectrosc. 183, 12 (1997).

${ }^{6}$ A. L. L. East, A. R. W. McKellar, and J. K. G. Watson, J. Chem. Phys. 109, 4378 (1998).

${ }^{7}$ E. M. Nour, L. H. Chen, M. M. Strube, and J. Laane, J. Phys. Chem. 88, 756 (1984).

${ }^{8}$ L. Krim and N. Lacome, J. Phys. Chem. A 102, 2289 (1998).

${ }^{9}$ J. R. Hezler, M. P. Casassa, and D. S. King, J. Phys. Chem. 95, 8086 (1991).

${ }^{10}$ M. P. Casassa, J. C. Stephenson, and D. S. King, J. Chem. Phys. 89, 1966 (1988).

${ }^{11}$ Y. Naitoh, Y. Fujimura, K. Honma, and O. Kajimoto, Chem. Phys. Lett. 205, 423 (1993)

${ }^{12}$ Y. Naitoh, Y. Fujimura, K. Honma, and O. Kajimoto, J. Phys. Chem. 99, 13652 (1995).

${ }^{13}$ C. M. Western, P. R. R. Langridge-Smith, B. J. Howard, and S. E. Novick, Mol. Phys. 44, 145 (1981).

${ }^{14}$ S. G. Kukolich, J. Am. Chem. Soc. 104, 4715 (1982).

${ }^{15}$ S. G. Kukolich and S. M. Sickafoose, Mol. Phys. 89, 1659 (1996).

${ }^{16}$ M. D. Brookes, A. R. W. McKellar, and T. Amano, J. Mol. Spectrosc. 185, 153 (1997)

${ }^{17}$ F. Legay and N. Legay-Sommaire, Chem. Phys. Lett. 211, 516 (1993).

${ }^{18}$ J. Billingsley and A. B. Callear, Trans. Faraday Soc. 67, 589 (1971).

${ }^{19}$ W. C. Natzle, D. Padowitz, and S. J. Sibener, J. Chem. Phys. 88, 7975 (1988).

${ }^{20}$ E. Hasselbrink, S. Jakubith, S. Nettesheim, M. Wolf, A. Cassuto, and G. Ertl, J. Chem. Phys. 92, 3154 (1990). 
${ }^{21}$ L. M. Cousins, R. J. Levis, and S. R. Leone, J. Chem. Phys. 91, 5731 (1989).

${ }^{22}$ St. J. Dixon-Warren, R. C. Jackson, J. C. Polanyi, H. Rieley, J. G. Shapter, and H. Weiss, J. Phys. Chem. 96, 10983 (1992).

${ }^{23}$ R. C. Jackson, J. C. Polanyi, and P. Sjövall, J. Chem. Phys. 102, 6308 (1995).

${ }^{24}$ A. Ludviksson, C. Huang, H. J. Jänsch, and R. M. Martin, Surf. Sci. 284, 328 (1993).

${ }^{25}$ W. A. Brown, P. Gardner, and D. A. King, J. Phys. Chem. 99, 7065 (1995).

${ }^{26}$ W. Tsang and J. T. Herron, J. Phys. Chem. Ref. Data 20, 609 (1991).

${ }^{27}$ S. K. Ross, J. W. Sutherland, S. Kuo, and R. B. Klemm, J. Phys. Chem. 101, 1104 (1997).

${ }^{28}$ P. L. James, I. R. Sims, and I. W. M. Smith, Chem. Phys. Lett. 276, 423 (1997).

${ }^{29}$ M. T. Vonk, J. A. Bacon, C. F. Giese, and W. R. Gentry, J. Chem. Phys. 106, 1353 (1997).

${ }^{30}$ X. Yang, E. H. Kim, and A. M. Wodtke, J. Chem. Phys. 96, 5111 (1992).

${ }^{31}$ K. A. Nguyen, M. S. Gordon, J. A. Montgomery, Jr., and H. H. Michels, J. Phys. Chem. 98, 10072 (1994).

${ }^{32}$ G. Chaban, M. S. Gordon, and K. A. Nguyen, J. Phys. Chem. A 101, 4283 (1997).

${ }^{33}$ W. H. Jones, J. Phys. Chem. 96, 594 (1992).

${ }^{34}$ S. Skaarup, P. N. Skancke, and J. E. Boggs, J. Am. Chem. Soc. 98, 6106 (1976).

${ }^{35}$ M. A. Benzel, C. E. Dykstra, and M. A. Vincent, Chem. Phys. Lett. 78, 139 (1981).

${ }^{36}$ R. D. Bardo, J. Phys. Chem. 86, 4658 (1982).

${ }^{37}$ T. J. Lee, J. E. Rice, G. E. Scuseria, and H. F. Schaefer III, Theor. Chim. Acta 75, 81 (1989).

${ }^{38}$ T. J. Lee, A. P. Rendell, and P. R. Taylor, J. Phys. Chem. 94, 5463 (1990).

${ }^{39}$ R. González-Luque, M. Merchán, and B. O. Roos, Theor. Chim. Acta 88, 425 (1994).

${ }^{40}$ A. L. L. East, J. Chem. Phys. 109, 2185 (1998).

${ }^{41}$ A. Stirling, I. Pápai, J. Mink, and D. R. Salahub, J. Chem. Phys. 100, 2910 (1994).

${ }^{42}$ B. S. Jursic and Z. Zdravkovski, Int. J. Quantum Chem. 54, 161 (1995).

${ }^{43}$ B. S. Jursic, Chem. Phys. Lett. 236, 206 (1995).

${ }^{44}$ A. Snis and I. Panas, Chem. Phys. 221, 1 (1997).

${ }^{45}$ J. F. Canty, E. G. Stone, S. B. H. Bach, and D. W. Ball, Chem. Phys. 216, 81 (1997).

${ }^{46}$ H. A. Duarte, E. Proynov, and D. R. Salahub, J. Chem. Phys. 109, 26 (1998).

${ }^{47}$ X. Yang, J. M. Price, J. A. Marck, C. G. Morgan, C. A. Rogaski, C. A. McGuire, E. H. Kim, and A. M. Wodtke, J. Phys. Chem. 97, 3944 (1993).

${ }^{48}$ D. W. Arnold and D. M. Neumark, J. Chem. Phys. 102, 7035 (1995).

${ }^{49}$ H. H. Michels and J. A. Montgomery, Jr., J. Chem. Phys. 88, 7248 (1988).

${ }^{50}$ K. A. Nguyen, M. S. Gordon, J. A. Montgomery, Jr., H. H. Michels, and D. R. Yarkony, J. Chem. Phys. 98, 3845 (1993).

${ }^{51}$ K. A. Nguyen, M. S. Gordon, and J. A. Boatz, J. Am. Chem. Soc. 116, 9241 (1994)

${ }^{52}$ D. R. Yarkony, in Modern Electronic Structure Theory, Part I, edited by D. R. Yarkony (World Scientific, Singapore, 1995), Chapter 11.

${ }^{53}$ J. M. Mercero, X. Lopez, J. E. Fowler, and J. Ugalde, J. Phys. Chem. A 101, 5574 (1997).

${ }^{54}$ K. Andersson, P. A. Malmqvist, B. O. Ross, A. J. Sadlej, and K. Wolinki, J. Phys. Chem. 94, 5483 (1990).

${ }^{55}$ K. Andersson, P. A. Malmqvist, and B. O. Ross, J. Chem. Phys. 96, 1218 (1992).

${ }^{56}$ K. Andersson, Theor. Chim. Acta 91, 31 (1995).

${ }^{57}$ K. Andersson and B. O. Ross, Int. J. Quantum Chem. 45, 591 (1993).

${ }^{58} \mathrm{~K}$. Andersson, and B. O. Ross, in Advanced Series in Physical Chemistry: Modern Electronic Structure Theory (Part I), edited by D. R. Yarkony (World Scientific, Singapore, 1995), Vol. 2, Chap. 2.

${ }^{59}$ B. O. Ross, K. Andersson, M. P. Fülscher, P. A. Malmqvist, L. SerranoAndrés, K. Pierloot, and M. Merchán, in Advances in Chemical Physics: New Methods in Computational Quantum Mechanics, edited by I. Prigogine and S. A. Rice (Wiley, New York, 1996), Vol. XCII, p. 219.

${ }^{60}$ B. O. Ross, Acc. Chem. Res. 32, 137 (1999).
${ }^{61}$ P. C. Hariharan and J. A. Pople, Theor. Chim. Acta 28, 213 (1973).

${ }^{62}$ R. Krishnan, J. S. Binkley, R. Seeger, and J. A. Pople, J. Chem. Phys. 72 , 650 (1980).

${ }^{63}$ M. J. Frisch, J. A. Pople, and J. S. Binkley, J. Chem. Phys. 80, 3265 (1984).

${ }^{64}$ T. H. Dunning, Jr., J. Chem. Phys. 90, 1007 (1989)

${ }^{65}$ K. A. Peterson and T. H. Dunning, Jr., J. Chem. Phys. 102, 2032 (1995).

${ }^{66}$ Extensible Computational Chemistry Environment Basis Set Database, Version 1.0, as developed and distributed by the Molecular Science Computing Facility, Environmental and Molecular Sciences Laboratory (EMSL) which is part of the Pacific Northwest Laboratory, P.O. Box 999, Richland, Washington 99352, and funded by the U.S. Department of Energy.

${ }^{67}$ MOLCAS, Version 4.1, K. Andersson, M. R. A. Blomberg, M. P. Fülscher, G. Karlström, R. Lindh, P. A. Malmqvist, P. Neogrády, J. Olsen, B. O. Ross, A. J. Sadlej, M. Schütz, L. Seijo, L. Serrano-Andrés, P. E. M. Siegbahn, and P. O. Widmark, Lund University, Sweden, 1998.

${ }^{68}$ W. C. Ermler, H. C. Hsieh, and L. B. Harding, Comput. Phys. Commun. 51, 257 (1988).

${ }^{69}$ G. Simons, R. G. Parr, and J. M. Finlan, J. Chem. Phys. 59, 3229 (1973).

${ }^{70}$ G. Simons, J. Chem. Phys. 61, 369 (1974).

${ }^{71}$ S. Klein, E. Kochanski, A. Strich, and A. J. Sadlej, Theor. Chim. Acta 94, 75 (1996).

${ }^{72}$ P. W. Atkins, Molecular Quantum Mechanics (Oxford University Press, Oxford, 1983), Chap. 13.

${ }^{73}$ S. F. Boys and F. Bernardi, Mol. Phys. 19, 553 (1979).

${ }^{74}$ K. P. Huber and G. Herzberg, Molecular Spectra and Molecular Structure. IV. Constants of Diatomic Molecules (Van Nostrand Reinhold, New York, 1979).

${ }^{75}$ R. M. Newmann, Astrophys. J. 161, 779 (1970).

${ }^{76}$ N. J. Bridge and A. D. Buckingham, Proc. R. Soc. London, Ser. A 295, 334 (1966).

${ }^{77}$ K. A. Peterson, R. A. Kendall, and T. H. Dunning, Jr., J. Chem. Phys. 99, 9790 (1993)

${ }^{78}$ K. A. Peterson, A. K. Wilson, D. E. Woon, and T. H. Dunning, Jr., Theor. Chim. Acta 97, 251 (1997).

${ }^{79}$ P. O. Widmark, P. A. Malmqvist, and B. O. Ross, Theor. Chim. Acta 77, 291 (1990).

${ }^{80}$ R. Sayós, R. Valero, J. M. Anglada, and M. González (unpublished).

${ }^{81}$ H. Akagi, Y. Fujimura, and O. Kajimoto, J. Chem. Phys. 111, 115 (1999).

${ }^{82}$ H. Tsurumaki, Y. Fujimura, and O. Kajimoto, J. Chem. Phys. 111, 592 (1999).

${ }^{83}$ S. Simon, M. Duran, and J. J. Dannenberg, J. Phys. Chem. A 103, 1640 (1999).

${ }^{84}$ E. P. F. Lee and T. G. Wright, Chem. Phys. Lett. 301, 467 (1999).

${ }^{85}$ F. Legay and N. Legay-Sommaire, J. Chem. Phys. 102, 7798 (1995).

${ }^{86}$ W. A. Guillory and C. E. Hunter, J. Chem. Phys. 50, 3516 (1969).

${ }^{87}$ P. O. Löwdin, Rev. Mod. Phys. 35, 496 (1963).

${ }^{88}$ E. R. Davidson and W. T. Borden, J. Phys. Chem. 87, 4783 (1983).

${ }^{89}$ L. Engelbrecht and B. Liu, J. Chem. Phys. 78, 3097 (1983).

${ }^{90}$ A. D. McLean, B. H. Lengsfield III, J. Pacansky, and Y. Ellinger, J. Chem. Phys. 83, 3567 (1985).

${ }^{91}$ M. Merchán, R. Pou-Amérigo, and B. O. Roos, Chem. Phys. Lett. 252, 405 (1996).

${ }^{92}$ P. S. Bagus and H. F. Schaeffer III, J. Chem. Phys. 56, 224 (1971).

${ }^{93}$ C. W. Bauschlicher and S. R. Langhoff, J. Chem. Phys. 89, 4246 (1988).

${ }^{94}$ A. Sánchez de Meras, M. B. Lepetit, and J. P. Malrieu, Chem. Phys. Lett. 172, 163 (1990)

${ }^{95}$ N. Guihery, J. P. Malrieu, D. Maynau, and K. Handrick, Int. J. Quantum Chem. 61, 45 (1997).

${ }^{96}$ L. Rodríguez-Monge and S. Larsson, Int. J. Quantum Chem. 61, 847 (1997).

${ }^{97}$ Gaussian 94, Revision B. 3, M. J. Frish, G. W. Trucks, M. Head-Gordon, P. M. W. Gill, M. W. Wong, J. B. Foresman, B. G. Johnson, H. B. Schlegel, M. A. Robb, E. S. Replogle, R. Gomperts, J. L. Andres, K. Raghavachari, J. S. Binkley, C. González, R. L. Martin, D. J. Fox, D. J. Defrees, J. Baker, J. J. P. Stewart, and J. A. Pople, Gaussian, Inc., Pittsburgh, PA, 1994. 